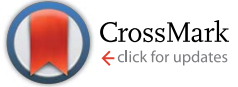

Cite this: J. Mater. Chem. B, 2015, 3 , 2472

Received 12th December 2014 Accepted 10th February 2015

DOI: $10.1039 / c 4 t b 02051 k$

www.rsc.org/MaterialsB

\section{Histamine-functionalized copolymer micelles as a drug delivery system in 2D and 3D models of breast cancer $\dagger$}

\author{
Yuning Zhang, ${ }^{a}$ Pontus Lundberg, ${ }^{\mathrm{b}}$ Maren Diether, ${ }^{\mathrm{a}}$ Christian Porsch, ${ }^{\mathrm{c}}$ \\ Caroline Janson, ${ }^{\mathrm{b}}$ Nathaniel A. Lynd, ${ }^{\mathrm{b}}$ Cosimo Ducani, ${ }^{\mathrm{d}}$ Michael Malkoch, ${ }^{\mathrm{c}}$ \\ Eva Malmström, ${ }^{c}$ Craig J. Hawker ${ }^{\mathrm{b}}$ and Andreas M. Nyström ${ }^{\star a}$
}

Histamine functionalized block copolymers based on poly(allyl glycidyl ether)-b-poly(ethylene oxide) (PAGE-b-PEO) were prepared with different ratios of histamine and octyl or benzyl groups using UVinitiated thiol-ene click chemistry. At neutral $\mathrm{pH}$, the histamine units are uncharged and hydrophobic, while in acidic environments, such as in the endosome, lysosomes, or extracellular sites of tumours, the histamine groups are positively charged and hydrophilic. $\mathrm{pH}$ responsible polymer drug delivery systems is a promising route to site specific delivery of drugs and offers the potential to avoid side effects of systemic treatment. Our detailed in vitro experiments of the efficacy of drug delivery and the intracellular localization characteristics of this library of NPs in 2D and 3D cultures of breast cancer revealed that the $50 \%$ histamine-modified polymer loaded with DOX exhibited rapid accumulation in the nucleus of free DOX within $2 \mathrm{~h}$. Confocal studies showed enhanced mitochondrial localization and lysosomal escape when compared to controls. From these combined studies, it was shown that by accurately tuning the structure of the initial block copolymers, the resulting self-assembled NPs can be designed to exploit histamine as an endosomal escape trigger and the octyl/benzyl units give rise to a hydrophobic core resulting in highly efficacious drug delivery systems (DDS) with control over intracellular localization. Optimization and rational control of the intracellular localization of both DDS and the parent drug can give nanomedicines a substantial increase in efficacy and should be explored in future studies.

\section{Introduction}

Polymer based materials and nanoparticles (NPs) are increasingly being investigated in a variety of biomedical applications, such as supporting cell growth, ${ }^{1}$ as protein carriers, ${ }^{2}$ gene $^{3-5}$ and chemotherapeutics delivery systems ${ }^{6,7}$ especially for cancer treatment. Unlike disaccharides, ${ }^{8}$ peptides, ${ }^{9}$ and inorganic $\mathrm{NPs}^{\mathbf{1 0}}$ that require further polymeric or liposomal modifications to serve as a drug delivery system (DDS), the amphiphilic block copolymers can self-assemble into core-shell NPs in aqueous

${ }^{a} I M M$ Institute of Environmental Medicine, Karolinska Institutet, SE-171 77, Stockholm, Sweden.E-mail: andreas.nystrom@ki.se

${ }^{b}$ Materials Research Laboratory, University of California, Santa Barbara, CA 93106, USA

${ }^{c}$ KTH Royal Institute of Technology, School of Chemical Science and Engineering, Department of Fibre and Polymer Technology, SE-100 44, Stockholm, Sweden

${ }^{d}$ Swedish Medical Nanoscience Center, Department of Neuroscience, Karolinska Institutet, SE-171 77, Stockholm, Sweden

$\dagger$ Electronic supplementary information (ESI) available: Detailed information regarding material synthesis and characterization, TEM images, MTT assays, drug wash-out MTT results, ATP assays for MDA-MB-231 cells in 2D culture, confocal images for heat map calculations, and mitochondria-stained 3D images can be found. See DOI: 10.1039/c4tb02051k solution without further modification. This combined with their ability to encapsulate a wide range of active compounds offers promise in the design of NPs for effective targeted delivery. ${ }^{11,12}$ Such NP platforms have been shown to enhance drug solubility, ${ }^{13-15}$ decrease side effects, ${ }^{16-18}$ and enhance the blood circulation time, ${ }^{19,20}$ which facilitates specific tumour uptake via the enhanced permeability and retention (EPR) effect. ${ }^{21-23}$ However, it is well known that cells protect themselves by entrapping most exogenous substances, including both small molecular drugs and NP-based DDS, in their endolysosomal system. ${ }^{\mathbf{2 4 , 2 5}}$ The entrapped substances are then partially or fully degraded which reduces their therapeutic effect. $^{\text {20,26,27 }}$ Consequently, a key issue when designing NPs for drug delivery has been enhancing cellular uptake by promoting endo-lysosomal escape of the carriers and their cargo into the cytoplasm. ${ }^{28,29}$ One widely studied approach for enabling NPs to escape the endo-lysosomal system is to utilize the $\mathrm{pH}$ difference between healthy cells and tumour cells. ${ }^{30-32}$ The $\mathrm{pH}$ in the extracellular fluids surrounding healthy tissues and in the blood stream is typically around 7.4, whereas the $\mathrm{pH}$ of extracellular fluids of tumour tissues is $\operatorname{lower}^{33}$ as well as intracellular organelles such as early endosomes (6.0-6.5) and lysosomes (4.5-5.5). ${ }^{34}$ In this acidic environment, positively 
charged polymers can cause endosomal/lysosomal rupture via the so-called "proton sponge effect". ${ }^{35,36}$ However, polymers with a permanent positive charge, like poly(ethylene imine) have been found to be cytotoxic to cells. ${ }^{37,38}$ Therefore, efforts have been directed toward the design of non-toxic nanocarriers with pH-responsive charge properties. Kataoka et al. have developed various polymer-based nanocarriers for $\mathrm{pDNA}^{3,39,40}$ and siRNA ${ }^{41,42}$ delivery. For example, the Kataoka group have recently reported a pH-reversible polymer platform based on maleic acid amide (MAA) for endosomal escape of siRNA by switching from negatively to positively charged MAA residues when the compound is exposed to an acidic environment. ${ }^{4}$ Another interesting alternative is to utilize histidine ${ }^{43}$ or histamine $^{44}$ groups as the $\mathrm{pH}$-responsive component due to their enhanced biocompatibility and appropriate $\mathrm{pH}$ response in acidic environments. While limited efforts have been made to use histidine-containing polymer NPs as gene ${ }^{45-47}$ or chemotherapeutic ${ }^{43,48,49}$ delivery systems, only a few research papers have been published on histamine-functionalized block copolymers as delivery platforms. ${ }^{44,50}$

We have previously reported on $\mathrm{pH}$-responsive poly(allyl glycidyl ether)- $b$-poly(ethylene oxide)- $b$-poly(allyl glycidyl ether) (PAGE- $b$-PEO- $b$-PAGE) polymers functionalized with histamine groups. ${ }^{51}$ These polymers rapidly form NPs in response to changes in $\mathrm{pH}$ and proved to be non-toxic to cells. But the hydrophobic components of our previous study needed to be further engineered to achieve the goal of drug delivery, as in the previous study the NPs were incapable of retaining the drug cargo in an efficient way. In the current work, we have elaborated on the performance of histamine-functionalized NPs as DDS which can partly escape from endo-lysosomes and relocate the drug into the mitochondria. Utilization of NPs for mitochondria targeting of chemotherapeutic compounds is a methodology that has emerged as a method for overcoming drug resistance. ${ }^{52-54}$ A library of different PAGE- $b$-PEO diblock copolymers were synthesized and functionalized with histamine and/or octyl/benzyl groups to yield a range of functional polymers that can form stable NPs in aqueous solutions. The addition of hydrophobic benzyl or octyl moieties was expected to enhance the drug loading and release behaviour of the NPs due to increased hydrophobicity. The effect of varying histamine content and the hydrophilic/hydrophobic ratio of NPs were thoroughly evaluated in $2 \mathrm{D}$ and $3 \mathrm{D}$ cell culture models.

\section{Experimental}

\subsection{Materials}

Dulbecco's modified Eagle's medium (DMEM), 3-(4,5-dimethylthiazol-2-yl)-2,5-diphenyltetrazolium bromide (MTT), phosphate buffered saline (PBS), formaldehyde solution, water, sodium dodecyl sulfate (SDS), methylcellulose powder, ethylene oxide (EO, 299.5\%), benzyl alcohol (BzOH, 99.8\%), 2,2-dimethoxy-2phenylacetophenone (DMPA, 99\%), octanethiol ( $\geq 98.5 \%$ ), and benzyl mercaptane (99\%) were purchased from Sigma-Aldrich and stored per the manufacturers' instructions. Phenol red-free DMEM with HEPES was obtained from Gibco. Fetal bovine serum (FBS) and penicillin-streptomycin solution were purchased from Hyclone Laboratories. Specific antibodies anti-EEA1 and anti-TGN46 - were obtained from Abcam Inc. The fluorescent dyes 4',6-diamidino-2-phenylindole (DAPI), LysoTracker, MitoTracker, and Donkey Anti-Mouse IgG antibody Alexa 647 were all purchased from Invitrogen and stored at $-20{ }^{\circ} \mathrm{C}$ as recommended. The CellTiter-Glo Luminescent Cell Viability Assay was obtained from Promega and stock solutions were prepared and stored following the manufacturer's instructions. Methanol $(\mathrm{MeOH})$ was purchased from Fisher Scientific. Allyl glycidyl ether (AGE) $\geq 99.0 \%$ (TCI) was degassed three times and distilled from butyl magnesium chloride before use. Potassium naphthalenide was prepared by dissolving recrystallized naphthalene $(10 \mathrm{~g})$ in dry tetrahydrofuran (THF, $250 \mathrm{~mL}$ ) and then added potassium metal (3 $\mathrm{g})$ under positive argon pressure. The system was closed with a septum and allowed to stir overnight with a glass-coated stir-bar. $N-2-\left(1 H^{-}\right.$ imidazol-4-yl)ethyl-4-mercaptobutanamide (Hist-SH) was synthesized as previously reported ${ }^{51}$ MCF-7, MDA-MB-231, and MDA-MB-468 cells were purchased from the American Type Culture Collection (ATCC) and maintained in DMEM supplemented with $10 \%(\mathrm{v} / \mathrm{v})$ fetal bovine serum (FBS), $100 \mathrm{U} \mathrm{mL}^{-1}$ penicillin, and $100 \mathrm{mg} \mathrm{mL}^{-1}$ streptomycin at $37{ }^{\circ} \mathrm{C}$ with $5 \%$ $\mathrm{CO}_{2}$.

\subsection{Instrumentation}

NMR spectra were recorded on a Varian VNMRS $600 \mathrm{MHz}$ using MeOD (Cambridge Isotope Laboratories) as the solvent. Fluorescence spectroscopy was performed on a Cary Eclipse from Varian using an excitation wavelength of $333.2 \mathrm{~nm}$, and emission spectra were collected between $350 \mathrm{~nm}$ and $420 \mathrm{~nm}$. Gel permeation chromatography (GPC) was performed on a TOSOH EcoSEC HLC-8320GPC system equipped with an EcoSEC RI detector and three columns (PSS PFG $5 \mu \mathrm{m}$; Microguard, $100 \AA$, and $300 \AA$ ) (MW resolving range: 100$\left.300000 \mathrm{~g} \mathrm{~mol}^{-1}\right)$ from PSS GmbH, using DMF $\left(0.2 \mathrm{~mL} \mathrm{~min}^{-1}\right)$ with $0.01 \mathrm{M} \mathrm{LiBr}$ as the mobile phase at $50{ }^{\circ} \mathrm{C}$. A conventional calibration method was created using narrow poly(methyl methacrylate) standards ranging from 700 to $2000000 \mathrm{~g}$ $\mathrm{mol}^{-1}$, and used to determine the average molar masses (number-average molar mass, $M_{\mathrm{n}}$ and weight-average molar mass, $\left.M_{\mathrm{w}}\right)$ and the dispersity $\left(D_{\mathrm{M}}=M_{\mathrm{w}} / M_{\mathrm{n}}\right)$. Corrections for flow rate fluctuations were made using toluene as an internal standard. PSS WinGPC Unity software version 7.2 was used to process the data. Dynamic light scattering was performed on a Malvern Zetasizer NanoTZ with 10 scans for each sample following a 2 min equilibration. TEM images were obtained with a FEI Morgagni 268(D) transmission electron microscope at $80 \mathrm{kV}$ at magnification 44000 . Apoptosis was evaluated on an Accuri C6 flow cytometer using FL-1/FL-3 to collect Annexin V FITC/PI fluorescence separately. MTT absorbance readings were obtained $18 \mathrm{~h}$ later with a BioTek Synergy ${ }^{\mathrm{TM}} \mathrm{MX}$ multi-mode micro plate reader operated by the Gen $5^{\mathrm{TM}}$ software at a wavelength of $570 \mathrm{~nm}$. The DOX fluorescence intensity was measured with the same equipment at an excitation wavelength of $485 \mathrm{~nm}$ and an emission wavelength of $595 \mathrm{~nm}$. The luminance reading was obtained with an Infinite 
F200 Tecan plate reader with luminance model. A Zeiss LSM 510 Meta confocal microscope with temperature control was used for both 2D and 3D imaging with lasers for DOX (543 nm laser, BP 560-615), Hoechst 33342 (405 nm laser, BP 420480 ), and deep red dyes (633 nm laser, LP 650). A $40 \times$ oilimmersion objective was used for the $2 \mathrm{D}$ models, and a $10 \times$ objective was applied for the $3 \mathrm{D}$ model. The $Z$-stack distance was set in the range of $100 \pm 10 \mu \mathrm{m}$. Data were processed and 3D images were reconstructed with Imars software. Co-localization analysis was conducted with the ImageJ software with the JACoP plugs in.

\subsection{Methods}

General procedure for synthesis of PAGE- $b$-PEO blockcopolymers. All polymerizations were carried out on a Schlenk line in custom thick-walled glass reactors fitted with threaded ACE-threads under argon atmosphere. The reactor was fitted with a burette containing THF from a dry solvent system, a flexible connector attached to a burette containing EO at $0{ }^{\circ} \mathrm{C}$, and an addition port capped with a septum. $\mathrm{BzOH}$ was first charged into the reactor followed by deprotonation with potassium naphthalenide (0.3 $\mathrm{M}$ in THF). Subsequently, AGE was charged into the reactor and the reaction was stirred with a glass-coated stir bar at room temperature overnight. THF was then added and a sample was collected and analyzed by ${ }^{1} \mathrm{H}$ NMR spectroscopy to confirm full conversion of AGE before the addition of EO. The reactor was then heated to $45{ }^{\circ} \mathrm{C}$ using an oil bath, and the reaction was allowed to proceed overnight. To terminate the reaction, degassed $\mathrm{MeOH}$ was added and the formed polymer was precipitated in hexanes, filtered, and dried under vacuum. The formed polymer was then analyzed by SEC and ${ }^{1} \mathrm{H}$-NMR spectroscopy. The degree of polymerization of the two blocks was determined by comparing the integral of the two benzylic protons at $4.53 \mathrm{ppm}$ with the integral from the two allylic protons at 5.28-5.14 ppm from the PAGE block and the backbone protons at 3.80-3.40 ppm resulting from both PAGE (5H per repeat unit) and PEO blocks $(4 \mathrm{H}$ per repeat unit). Yield 97\%. ${ }^{1} \mathrm{H}-\mathrm{NMR}(\mathrm{MeOD}) \delta(\mathrm{ppm})=3.40-3.80$ (m, backbone), 4.02 (s, -O- $\mathrm{CH}_{2}-$ ), 4.55 (s, $\left.\mathrm{Ar}-\mathrm{CH}_{2}-\mathrm{O}-\right)$, 5.16-5.17 (d, $J=6 \mathrm{~Hz}$, $\mathrm{CH}_{2}-\mathrm{CH}-$ ), 5.27-5.30 (d, $J=18 \mathrm{~Hz}, \mathrm{CH}_{2}-\mathrm{CH}-$ ), 5.91 (m, $-\mathrm{CH}_{2}-\mathrm{CH}-\mathrm{CH}_{2}$ ), 7.35 (m, Ar-). Molecular weight by ${ }^{1} \mathrm{H}-\mathrm{NMR}$ : $\mathrm{PAGE}_{22}-\mathrm{PEO}_{246}(\mathrm{LLO})=13300 \mathrm{~g} \mathrm{~mol}^{-1} ; \mathrm{PAGE}_{20}-\mathrm{PEO}_{430}(\mathrm{LH} 0)=$ $21200 \mathrm{~g} \mathrm{~mol}^{-1}, \mathrm{PAGE}_{41}-\mathrm{PEO}_{486}(\mathrm{HH} 0)=26100 \mathrm{~g} \mathrm{~mol}^{-1}$. Molecular weight by SEC (DMF): $\mathrm{PAGE}_{22}-\mathrm{PEO}_{246}$ (LLO) $=11000$ $\mathrm{g} \mathrm{mol}^{-1}$ (PDI = 1.1); $\mathrm{PAGE}_{20}-\mathrm{PEO}_{430}(\mathrm{LHO})=19700 \mathrm{~g} \mathrm{~mol}^{-1}$ $(\mathrm{PDI}=1.1) ; \mathrm{PAGE}_{41}-\mathrm{PEO}_{486}(\mathrm{HHO})=19300 \mathrm{~g} \mathrm{~mol}^{-1}(\mathrm{PDI}=1.1)$.

General procedure for functionalization of PAGE- $b$-PEO block-copolymers using thiol-ene chemistry. A $25 \mathrm{~mL}$ round bottom flask equipped with a stir bar was charged with $1.0 \mathrm{~g}$ PAGE- $b$-PEO block copolymer, 1.3 equivalents of thiols based on the number of allyls on the polymer, and $8 \mathrm{~mL}$ of $\mathrm{MeOH}$ and capped with a septum. Once everything was dissolved, 0.05 equivalents of photoinitiator, 2,2-dimethoxy-2-phenylacetophenone DMPA, based on the number of allyls on the polymer was added. The solution was then put in an ice bath and sparged with argon for $1 \mathrm{~min}$ followed by irradiation of UV- light (365 nm) for $60 \mathrm{~min}$. The functionalized polymer was then purified by dialysis in $3 \times 1 \mathrm{~L} \mathrm{MeOH}$ using a dialysis membrane with MWCO of $3500 \mathrm{Da}$. Finally, the functionalized polymer was isolated by evaporation of the $\mathrm{MeOH}$ and analysed by ${ }^{1} \mathrm{H}-\mathrm{NMR}$. Yield 87\%. ${ }^{1} \mathrm{H}-\mathrm{NMR}(\mathrm{MeOD}) \delta(\mathrm{ppm})=[\mathrm{P}(\mathrm{HGE}-\mathrm{OGE})-\mathrm{PEO}]=$ $0.92\left(\mathrm{~s}, \mathrm{CH}_{3}-\mathrm{CH}_{2}-\right), 1.32\left(\mathrm{~m},-\mathrm{CH}_{2}-\mathrm{CH}_{2}-\mathrm{CH}_{2}-\mathrm{CH}_{2}-\mathrm{CH}_{3}\right), 1.41$ (s, $\left.-\mathrm{CH}_{2}-\mathrm{CH}_{2}-\mathrm{CH}_{2}-\mathrm{S}-\right), 1.59$ (s, $\left.-\mathrm{CH}_{2}-\mathrm{CH}_{2}-\mathrm{S}-\right), 1.84$ (m, $-\mathrm{O}-\mathrm{CH}_{2}-\mathrm{CH}_{2}-\mathrm{CH}_{2}-\mathrm{S}-$ and $\left.-\mathrm{S}-\mathrm{CH}_{2}-\mathrm{CH}_{2}-\mathrm{CH}_{2}-\mathrm{C}(=\mathrm{O})-\right), 2.30$ (t, $J=$ $\left.12 \mathrm{~Hz},-\mathrm{CH}_{2}-\mathrm{C}(=\mathrm{O})-\mathrm{NH}-\right)$, 2.52-2.60 (m, -S- $\mathrm{CH}_{2}-\mathrm{CH}_{2}-\mathrm{CH}_{2}-\mathrm{O}-$, $-\mathrm{S}-\mathrm{CH}_{2}-\mathrm{CH}_{2}-\mathrm{CH}_{2}-\mathrm{C}(=\mathrm{O})-$ and $\left.-\mathrm{S}-\mathrm{CH}_{2}-\mathrm{CH}_{2}-\right), 2.78(\mathrm{t}, J=12 \mathrm{~Hz}$, $\left.>\mathrm{C}-\mathrm{CH}_{2}-\mathrm{CH}_{2}-\mathrm{NH}-\mathrm{C}(=\mathrm{O})-\right), 3.43\left(\mathrm{t}, \mathrm{J}=12 \mathrm{~Hz},-\mathrm{CH}_{2}-\mathrm{NH}-\mathrm{C}(=\mathrm{O})-\right)$, 3.45-3.80 (m, backbone and - $\left.-\mathrm{CH}_{2}-\mathrm{CH}-\right), 4.56$ (s, $\left.\mathrm{Ar}-\mathrm{CH}_{2}-\mathrm{O}-\right)$, 6.85 (s, -NH-CH-C<), $7.36(\mathrm{~m}, \mathrm{Ar}-), 7.59(\mathrm{~s},-\mathrm{NH}-\mathrm{CH}=\mathrm{N}-) .{ }^{1} \mathrm{H}-$ $\mathrm{NMR}(\mathrm{MeOD}) \delta(\mathrm{ppm})=[\mathrm{P}(\mathrm{HGE}-\mathrm{BGE})-\mathrm{PEO}]=1.78-1.84(\mathrm{~m},-\mathrm{O}-$ $\mathrm{CH}_{2}-\mathrm{CH}_{2}-\mathrm{CH}_{2}-\mathrm{S}-$ and $-\mathrm{S}-\mathrm{CH}_{2}-\mathrm{CH}_{2}-\mathrm{CH}_{2}-\mathrm{C}(=\mathrm{O})-$ ), 2.47-2.55 (m, $-\mathrm{S}-\mathrm{CH}_{2}-\mathrm{CH}_{2}-\mathrm{CH}_{2}-\mathrm{O}-$ and $\left.-\mathrm{S}-\mathrm{CH}_{2}-\mathrm{CH}_{2}-\mathrm{CH}_{2}-\mathrm{C}(=\mathrm{O})-\right), 2.76$ (t, $J=$ $\left.12 \mathrm{~Hz},>\mathrm{C}-\mathrm{CH}_{2}-\mathrm{CH}_{2}-\mathrm{NH}-\mathrm{C}(=\mathrm{O})-\right), 3.41$ (t, $J=12 \mathrm{~Hz},-\mathrm{CH}_{2}-\mathrm{NH}-$ $\mathrm{C}(=\mathrm{O})-$ ), 3.45-3.80 (m, backbone, $-\mathrm{O}-\mathrm{CH}_{2}-\mathrm{CH}-$, and $-\mathrm{S}-\mathrm{CH}_{2}-\mathrm{Ar}$ ), 4.52 (s, $\left.\mathrm{Ar}-\mathrm{CH}_{2}-\mathrm{O}-\right), 6.83$ (s, $\left.-\mathrm{NH}-\mathrm{CH}-\mathrm{C}<\right), 7.20-7.32\left(\mathrm{~m}, \mathrm{Ar}-\mathrm{CH}_{2}-\right.$ $\mathrm{S}-$ and $\left.\mathrm{Ar}-\mathrm{CH}_{2}-\mathrm{O}\right), 7.59(\mathrm{~s},-\mathrm{NH}-\mathrm{CH}=\mathrm{N}-)$. Poor solubility made SEC analysis impossible after functionalization.

Preparation of NPs and DOX-loaded NPs. NPs were formed by mixing $10 \mathrm{mg}$ of materials into $10 \mathrm{~mL}$ PBS $\left(1 \mathrm{mg} \mathrm{mL}{ }^{-1}\right)$ under vigorous stirring for $6 \mathrm{~h}$ followed by letting them stand without stirring for $12 \mathrm{~h}^{51}$ DOX-loaded NPs were prepared via a twophase emulsion method as described previously. ${ }^{55}$ Generally, 2 $\mathrm{mL}$ of $0.5 \mathrm{mg} \mathrm{mL}{ }^{-1}$ of DOX stock solution in $\mathrm{CH}_{2} \mathrm{CL}_{2}$ (with 3 fold molar equivalents of triethylamine (TEA) to DOX) were mixed with $4 \mathrm{~mL}$ of PBS solution containing $1 \mathrm{mg}$ of polymer. The mixture was stirred gently $(100 \mathrm{rpm})$ by a magnetic stirrer, and the organic solvent was allowed to evaporate fully. The resulting solution was transferred into a spin filtration device $(3 \mathrm{kDa}$ MWCO) to remove unloaded DOX by centrifugation at $769 \times g$ for $10 \mathrm{~min}$. The vial was refilled with PBS, and the process was repeated until all free DOX was removed. The DOX concentration in the NPs was determined by UV-Vis after disaggregation of the NPs using dimethylformamide (DMF) in $\mathrm{H}_{2} \mathrm{O}(4: 1)$ using a standard curve of DOX absorbance at $490 \mathrm{~nm} .^{55,56}$

Dynamic light scattering measurement. The hydrodynamic diameters of the NPs and DOX-NPs were evaluated with a Malvern Zetasizer NanoTZ at $25^{\circ} \mathrm{C}$ and $37^{\circ} \mathrm{C}$, respectively, in PBS. Samples were analyzed in triplicate, and pure NPs were analyzed at a concentration of $0.25 \mathrm{mg} \mathrm{mL}^{-1}$. DOX-NPs were measured immediately after removing free DOX.

Transmission electron microscopy (TEM). $3 \mu \mathrm{L}$ each of NPs or DOX-NPs (ca. $50 \mu \mathrm{g} \mathrm{mL} \mathrm{m}^{-1}$ polymer conc.) was placed on a on a glow-discharged, carbon-coated Formvar grid (Electron Microscopy Sciences) for 20 seconds. The liquid drop was removed and the sample was stained with $2 \%(\mathrm{w} / \mathrm{v})$ aqueous uranyl formate solution for another 20 seconds. TEM images were obtained with a FEI Morgagni 268(D) Transmission Electron Microscope.

In vitro drug release. A total of $3 \mathrm{~mL}$ of free $\mathrm{DOX}$ or DOX-NP solution was transferred to dialysis cassettes (MWCO 3,500, Slide-A-Lyzer G2, Thermo) that were suspended in 4 L of PBS (pH 6.0 and 7.4, respectively) at $37{ }^{\circ} \mathrm{C}$ with magnetic stirring. Aliquots (triplicates of $10 \mu \mathrm{L}$ each) from the inside of the 
cassettes were collected at the following time-points: $0,2,8,10$, $12,24,48$, and $72 \mathrm{~h}$. A total of $100 \mu \mathrm{L}$ of DMF in $\mathrm{H}_{2} \mathrm{O}(4: 1)$ was added to each sample to disaggregate the NPs. The resulting solutions were transferred into 96-well fluorescence plates, and the fluorescence intensity was determined with a BioTek Synergy $^{\mathrm{TM}}$ MX multi-mode micro plate reader.

Cell culture and 3D spheroids formation. 3D spheroids were generated from MDA-MB-231 cells as described by Heuchel et $a l .^{57}$ Generally, cells were detached with trypsin, washed with PBS, and suspended in complete DMEM (without rho) medium supplemented with $20 \%$ methylcellulose at a concentration of 3000 cells per well. ${ }^{57}$ Cell suspensions were transferred into 96well plates (round bottom) at $100 \mu \mathrm{L}$ per well and incubated at $37{ }^{\circ} \mathrm{C}$ for a minimum of $48 \mathrm{~h}$ to form 3D spheroids.

MTT assays. MCF-7, MDA-MB-231, and MDA-MB-468 breast cancer cells were harvested with trypsin and seeded into 96-well plates at a density of $1 \times 10^{4}$ cells per well in $100 \mu \mathrm{L}$ DMEM medium. Old medium was replaced by fresh medium containing various types and concentrations of the NPs after $24 \mathrm{~h}$ preculture (5 replicates were set for each concentration) and 3 trials for each experiment. The experiments were planned according to our previous report on a similar polymer system. After the desired incubation times, $10 \mu \mathrm{L}$ of $5 \mathrm{mg} \mathrm{mL}^{-1}$ MTT reagent were added into each well followed by $100 \mu \mathrm{L}$ of $10 \%$ SDS solution $4 \mathrm{~h}$ later. Absorbance readings were obtained with a BioTek Synergy $^{\mathrm{TM}}$ MX multi-mode micro plate reader $18 \mathrm{~h}$ later.

ATP assays. MDA-MB-231 spheroids or 2D cultures in 96-well plates were treated with $100 \mu \mathrm{L}$ of medium containing NPs, DOX, or DOX-NPs at concentrations ranging from $0.01-10 \mu \mathrm{g}$ $\mathrm{mL}^{-1}$ ( 6 replicates for each concentration) and incubated under standard culture conditions for $72 \mathrm{~h}$. A total of $120 \mu \mathrm{L}$ of medium was removed carefully (to avoid loss of spheroids) and $80 \mu \mathrm{L}$ of CellTiter-Glo Luminescent reagent were added into each well. Plates were shielded from light and put on a shaker with gentle agitation for $20 \mathrm{~min}$. The mixtures from each well were then transferred into white 96-well plates and the resulting luminescence was quantified using an Infinite F200 plate reader.

Apoptosis assays. MDA-MB-468 cells were pre-cultured in 6 well plates for $24 \mathrm{~h}$ before treatment with $1 \mu \mathrm{g} \mathrm{mL}{ }^{-1}$ of DOX, DOX-NPs or $50 \mu \mathrm{g} \mathrm{mL} \mathrm{m}^{-1}$ of NPs for another $12 \mathrm{~h}$ or $72 \mathrm{~h}$. Cells were harvested and washed with PBS two times before they were double stained with FITC-labelled Annexin V and propidium iodide (PI). Samples were analysed with an Accuri C6 (BD Science) flow cytometer by counting 10000 events in the population. FITC-labelled Annexin V was excited by the $488 \mathrm{~nm}$ laser and collected in the FL-1 $(533 / 30 \mathrm{~nm})$ detector, and propidium iodide fluorescence was collected in the FL-3 (>670 nm) detector. Data was analyzed using the BD Accuri C6 Analysis software.

In vitro DOX localization studies. For the $2 \mathrm{D}$ confocal studies, breast cancer cells were seeded at a density of $1 \times 10^{5}$ cells per well in glass bottom dishes (P35G-0-10-C, MatTek) precultured for $24 \mathrm{~h}$ at $37{ }^{\circ} \mathrm{C}$. Cells were treated with $2 \mu \mathrm{g} \mathrm{mL} \mathrm{m}^{-1}$ of DOX or DOX-NPs for $2 \mathrm{~h}$ then washed with PBS twice and stained with Hoechst (5 $\mu \mathrm{g} \mathrm{mL}^{-1}$ ), LysoTracker (100 nM), or MitoTracker (100 nM). For the EEA1 and TGN staining, cells were fixed in $4 \%$ formaldehyde followed by incubation in $1 \%$ BSA in $0.1 \%$ PBS-Tween for $1 \mathrm{~h}$ and then incubation with primary antibody (1/200 dilution, ab70521 EEA1 or ab50595 TGN) overnight at $4{ }^{\circ} \mathrm{C}$. Finally, cells were incubated with $5 \mu \mathrm{g}$ $\mathrm{mL}^{-1}$ of the secondary antibody (donkey anti-mouse IgG, Alexa Fluor $\left.{ }^{\circledR} 647\right) .{ }^{58,59}$ The prepared samples were visualized with a Zeiss LSM 510 Meta confocal microscope with a temperature control chamber.

For the 3D imaging, spheroids were incubated with $2 \mu \mathrm{g}$ $\mathrm{mL}^{-1}$ DOX or DOX-NPs for $4 \mathrm{~h}$ and transferred into an Eppendorf tube and gently spun for $15 \mathrm{~s}$. The supernatant was discarded and PBS was added. The washing step was repeated 3

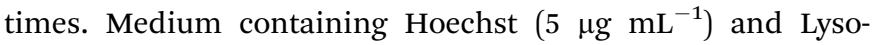
Tracker Deep Red (100 nM) or MitoTracker Deep Red FM (100 $\mathrm{nM}$ ) was then added and incubated for another $15 \mathrm{~min}$. Spheroids were washed with PBS twice then suspended in glass bottom dishes (P35G-0-10-C, MatTek). The prepared samples were visualized with a Zeiss LSM 510 Meta confocal microscope with a temperature control chamber.

Statistical Analysis. The MTT assays and ATP assays are presented as mean values with standard deviation (SD). Statistical data analysis was performed via ANOVA followed by a post hoc test (Tukey HSD, alpha 0.05) using KaleidaGraph v4.1. Significance levels were set as $* * * P<0.001, * * P<0.01$, and $* P<$ 0.05 .

\section{Results and discussion}

\subsection{Synthesis of the polymers}

We have previously reported on the synthesis of novel histamine-functional poly(allyl glycidyl ether)- $b$-poly(ethylene oxide)$b$-poly(allyl glycidyl ether) (PAGE- $b$-PEO- $b$-PAGE) triblock copolymers with interesting $\mathrm{pH}$-responsive hydrogelation behaviours. ${ }^{51}$ The fact that histamine has a $\mathrm{p} K_{\mathrm{a}}$ in a physiological relevant $\mathrm{pH}$ range (6.0-7.4) in combination with its biocompatibility makes it highly useful in a number of biomedical applications. ${ }^{\mathbf{4 4 , 5 0 , 6 0 , 6 1}}$ For instance, Wooley et al. $^{\mathbf{4 4}}$ developed histamine-containing shell cross-linked NPs for siRNA delivery and found that the histamine content contributed to reduced cytotoxicity and assisted in endosomal escape. Liu et al. ${ }^{50}$ utilized an amphiphilic chondroitin sulfate-histamine conjugate to achieve pH-triggered doxorubicin (DOX) release in vitro. In the present study, structure-property relationships for histamine-functionalized polymers were investigated in the form of NPs for therapeutic delivery with a focus on the effect of histamine protonation on NP performance.

In this study, a diverse polymer library of histamine-functionalized amphiphilic copolymers was synthesized by ring opening polymerization followed by post-functionalization through UV-initiated thiol-ene click chemistry. ${ }^{51,62,63}$ Poly(allyl glycidyl ether)- $b$-poly(ethylene oxide) (PAGE- $b$-PEO) diblock copolymers were initially synthesized and the polymerization reactions monitored by ${ }^{1} \mathrm{H}-\mathrm{NMR}$ and size exclusion chromatography (SEC) (Scheme 1). Three different well-defined polymer precursors with varying allyl glycidyl (AGE)/ethylene oxide (EO) compositions were targeted (Table 1). The AGE-blocks of the copolymers were subsequently functionalized by 

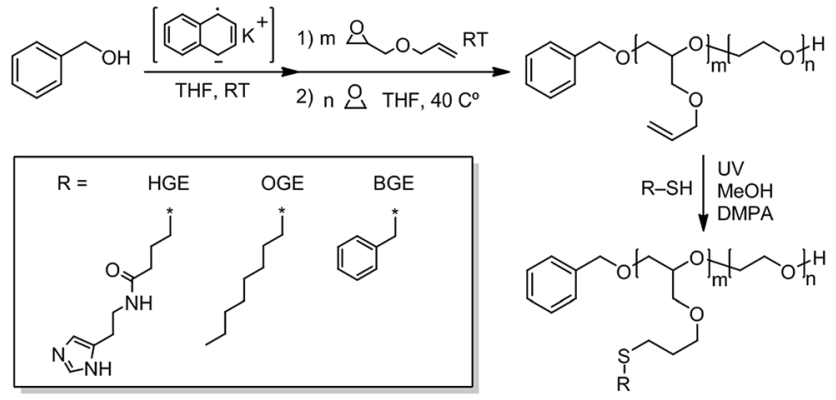

Scheme 1 Synthetic route to diblock PAGE- $b$-PEO copolymer and its functionalized analogues PHGE- $b$-PEO, P(HGE-OGE)- $b$-PEO, POGE$b$-PEO, P(HGE-BGE)- $b$-PEO, and PBGE- $b$-PEO.

photochemical thiol-ene chemistry utilizing thiol-functional building blocks as illustrated in Scheme 1. By targeting different ratios of histamine glycidyl ether (HGE), octyl glycidyl ether (OGE), and benzyl-functional glycidyl ether (BGE) thiols, the role of the hydrophobic core domain on the loading and release of the chemotherapeutic cargo can be explored. These modifications resulted in a diverse library of amphiphilic diblock copolymers with different degrees of histamine functionality of the hydrophobic block, and different lengths of the hydrophilic PEO block as shown in Table 1 and (Table ESI $1 \dagger$ ). To condense the naming of each NP's, we created a naming system to represent each material based on the molecular weight of the hydrophobic/hydrophilic components. LL = low PXGE Mw and low PEO Mw group; LH = low PXGE $\mathrm{Mw}$ and high PEO Mw group; $\mathrm{HH}=h$ igh PXGE $\mathrm{Mw}$ and $h$ igh PEO Mw group; ( $\mathrm{X}$ in PXGE $=(\mathrm{A})$ allyl, $(\mathrm{O})$ octyl, $(\mathrm{H})$ histamine, (B) benzyl). The thiolene reaction was monitored by ${ }^{1} \mathrm{H}-\mathrm{NMR}$ and verified by quantitative functionalization. ${ }^{1} \mathrm{H}-\mathrm{NMR}$ spectra of neat $\mathrm{PAGE}_{22^{-}}$ $b$ - $\mathrm{PEO}_{246}$ (LL0), $\mathrm{P}\left(\mathrm{HGE}_{11}-\mathrm{OGE}_{11}\right)-\mathrm{PEO}_{246}$ (LL3), and $\mathrm{P}\left(\mathrm{HGE}_{10^{-}}\right.$ $\left.\mathrm{BGE}_{12}\right)-\mathrm{PEO}_{246}$ (B2) are shown in Fig. 1. The appearance of the characteristic histamine (s and r), octyl (aa and ab), and benzyl $(\mathrm{u}, \mathrm{v}$, and $\mathrm{x})$ resonances, as well as the disappearance of the allyl shift (k), can be observed in the spectra. As a result of the complex amphiphilic compositions of the functionalized diblock copolymers complete polymer dissolution only occurred in methanol or in aqueous solution (which induced micelle formation), and this prohibited SEC analysis of the final products. However no chain scission or change in the degree of polymerization is expected when compared to the fully characterized, starting diblock copolymers.

\subsection{Characterization of the polymer NPs}

Fig. 2 TEM the hydrodynamic sizes of the NPs and DOX-NPs were determined by dynamic light scattering. Apart from HH1, the diameter (by number mean) of most materials ranged in size from $16 \mathrm{~nm}$ to $59 \mathrm{~nm}$ prior to drug encapsulation and the corresponding drug-loaded DOX-NPs had larger diameters as shown in Table 1. These sizes are larger compared to the size calculated from TEM images $(6-20 \mathrm{~nm})$ shown in Fig. 2 . This is a result of TEM measuring the dry NP sizes rather than hydrodynamic sizes. It was also noted that samples, such as LH5 and LL2, had aggregation problems upon drug loading as evidenced by their hydrodynamic size increasing to several hundred $\mathrm{nm}$ (Table 1) and large aggregated objects seen in the TEM image (Fig. ESI 1†). This indicated that DOX encapsulation induced aggregation of the material, similar to our previous report. ${ }^{55} \mathrm{The}$ loading efficiencies of DOX in the polymer NPs were found to be very similar regardless of the polymer composition and ranged from $15 \%$ to $30 \%$ (wt/wt) except for HH3 (12\%), LH2 (36\%), and B2 (44\%). These loading efficiencies fall in the middle of other

Table 1 Characteristics of NPs and DOX-NPs

\begin{tabular}{|c|c|c|c|c|c|c|}
\hline $\operatorname{Codes}^{a}$ & Materials & $\begin{array}{l}\text { Histamine } v s \text {. } \\
\text { other thiol (\%) }\end{array}$ & Number mean $^{b}(\mathrm{~d} n m)$ & $\mathrm{CMC}^{c}\left(\mu \mathrm{g} \mathrm{mL}^{-1}\right)$ & $\begin{array}{l}\text { Number mean } \\
(\mathrm{d} n \mathrm{~nm})\end{array}$ & $\begin{array}{l}\text { Loading efficiency } \\
(\%)\end{array}$ \\
\hline LL1 & $\mathrm{POGE}_{22}-b-\mathrm{PEO}_{246}$ & 0 & $16 \pm 1$ & 4.0 & $80 \pm 6$ & 23 \\
\hline LL2 & $\mathrm{P}\left(\mathrm{HGE}_{7}-\mathrm{OGE}_{15}\right)-b-\mathrm{PEO}_{246}$ & 32 & $16 \pm 0$ & 3.8 & $260 \pm 212$ & 28 \\
\hline LL3 & $\mathrm{P}\left(\mathrm{HGE}_{11}-\mathrm{OGE}_{11}\right)-b-\mathrm{PEO}_{246}$ & 48 & $28 \pm 0$ & 4.3 & $42 \pm 16$ & 15 \\
\hline B1 & $\mathrm{PBGE}_{22}-b-\mathrm{PEO}_{246}$ & 0 & $26 \pm 5$ & 8.1 & $38 \pm 1$ & 23 \\
\hline $\mathrm{B} 2$ & $\mathrm{P}\left(\mathrm{HGE}_{10}-\mathrm{BGE}_{12}\right)-b-\mathrm{PEO}_{246}$ & 44 & $18 \pm 1$ & 4.2 & $25 \pm 5$ & 44 \\
\hline LH1 & $\mathrm{POGE}_{20}-b-\mathrm{PEO}_{430}$ & 0 & $59 \pm 1$ & 5.7 & $56 \pm 3$ & 29 \\
\hline $\mathrm{LH} 2$ & $\mathrm{P}\left(\mathrm{HGE}_{4}-\mathrm{OGE}_{16}\right)-b-\mathrm{PEO}_{430}$ & 22 & $49 \pm 1$ & 7.9 & $49 \pm 2$ & 37 \\
\hline LH3 & $\mathrm{P}\left(\mathrm{HGE}_{10}-\mathrm{OGE}_{10}\right)-b-\mathrm{PEO}_{430}$ & 51 & $39 \pm 2$ & 9.4 & $38 \pm 4$ & 15 \\
\hline LH4 & $\mathrm{P}\left(\mathrm{HGE}_{16}-\mathrm{OGE}_{4}\right)-b-\mathrm{PEO}_{430}$ & 82 & $18 \pm 5$ & 8.4 & $25 \pm 4$ & 15 \\
\hline
\end{tabular}

${ }^{a} \mathrm{LL}=$ low PXGE Mw and low PEO Mw group; LH = low PXGE Mw and high PEO Mw group; HH = high PXGE Mw and high PEO Mw group; (X in $\mathrm{PXGE}=\mathrm{A}, \mathrm{O}, \mathrm{H}) . \mathrm{B}=\mathrm{BGE}$ unit group. ${ }^{b}$ d.n.m = diameter in $\mathrm{nm}$ range. ${ }^{c}$ Values obtained at $\mathrm{pH}$ 7.4. 


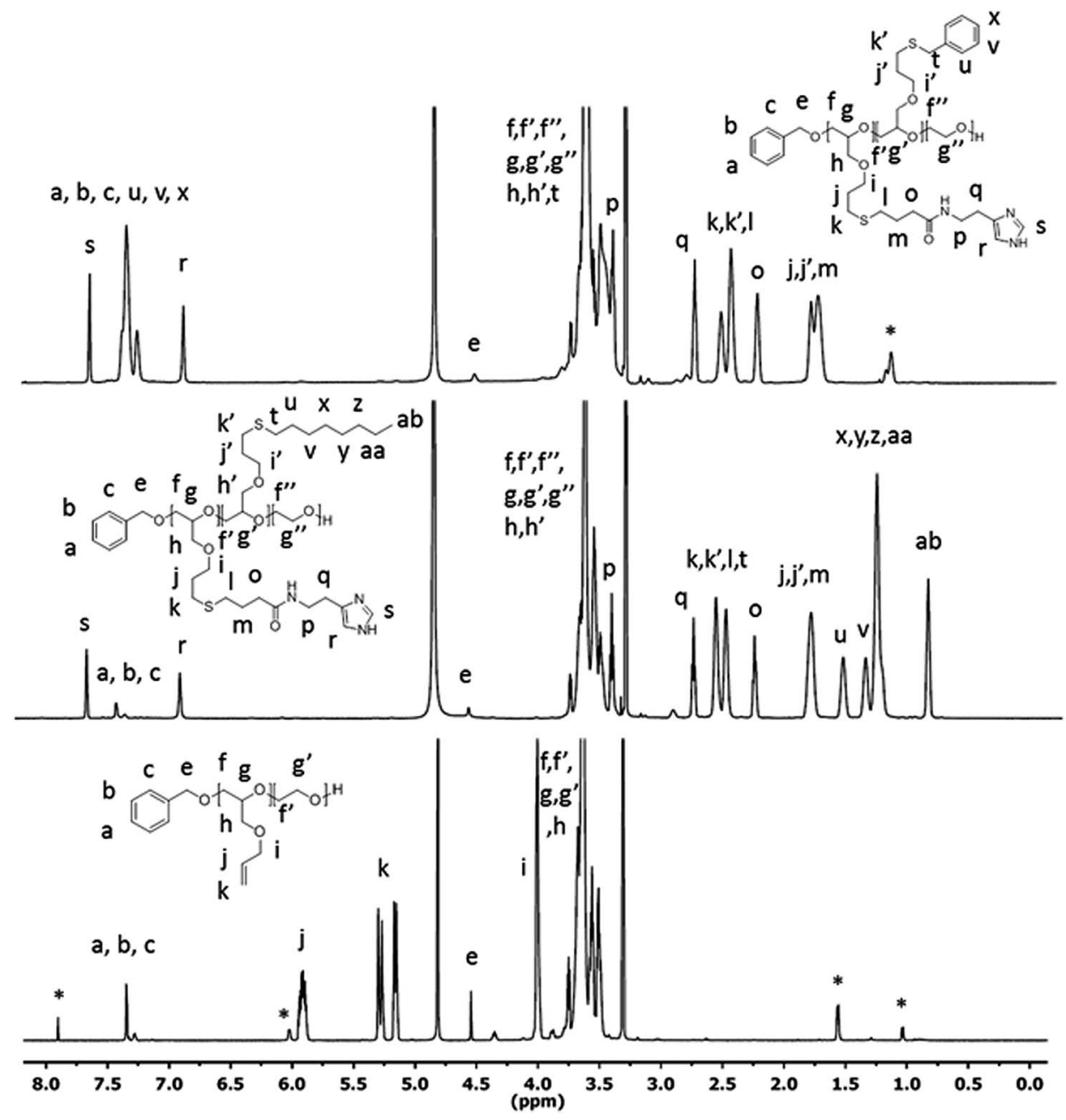

Fig. $1{ }^{1} \mathrm{H}-\mathrm{NMR}$ (MeOD) of $\mathrm{PAGE}_{22}-b-\mathrm{PEO}_{246}$ (bottom), $\mathrm{P}\left(\mathrm{HGE}_{11}-\mathrm{OGE}_{11}\right.$ )- $b-\mathrm{PEO}_{246}$ (middle), and $\mathrm{P}\left(\mathrm{HG} \mathrm{E}_{10}-\mathrm{BGE}_{12}\right)-b-\mathrm{PEO} 246$ (top). *Corresponds to resonances from the allyl isomer.

polymer carriers that physically encapsulate DOX, where loading efficiencies from $8 \%$ to $51 \%$ are typically observed. ${ }^{64-66}$

The critical micelle concentration (CMC) represents the minimal concentration of polymer required to maintain the micellar structure. NPs with lower CMCs are considered better for systemic in vivo drug delivery applications due to reduced risk of structural collapse followed by burst release of the cargo upon dilution in the blood stream. The CMC values of the polymers are given at $\mathrm{pH} 7.4$ in Table 1 and at pH 5.0 in Table ESI $1 \dagger$ and indicate that higher amounts of histamine modification result in higher CMC values. NPs with 0-50\% histamine in the hydrophobic cores have CMCs below $10 \mu \mathrm{g} \mathrm{mL}{ }^{-1}$ at both $\mathrm{pH}$ levels investigated, a value sufficiently low for drug delivery applications. ${ }^{67}$ The fluorescence intensities of free DOX and DOX-LL3 were compared at the same concentration of DOX (50 $\mu \mathrm{g} \mathrm{mL}^{-1}$ ) by fluorescence measurements (Fig. ESI $2 \dagger$ ). This indicated that the fluorescence was quenched to a large extent which suggested that the drug is located in a hydrophobic compartment of the NP. ${ }^{68}$

\subsection{DOX release in vitro}

The drug release properties for all DOX-NPs produced in this work were first evaluated in vitro in PBS at $\mathrm{pH} 6.0$ to mimic the $\mathrm{pH}$ in the early endosome and $\mathrm{pH} 7.4$ as a general $\mathrm{pH}$ value in healthy tissue. This simple model for release at different $\mathrm{pH}$ values does not mimic the complex in vivo situation, but it does allow us to compare the release kinetics from these materials to the release kinetics of other compounds under standardized conditions. The histamine groups were expected to be sensitive to differences in $\mathrm{pH}$ in the environment, but the release curves at different pH shown in Fig. 3 (Fig. ESI 3A and $\mathrm{B} \dagger$ ) did not show any significant differences between the same materials after 72 h. However, DOX-NPs with 50\% histamine (DOX-LL3 and DOX$\mathrm{HH} 2$ ) showed lower release rates within 24 and $72 \mathrm{~h}$ at $\mathrm{pH} 6.0$ compared to pH 7.4 (Fig. 2 and ESI 3C†). This might be a result of the hydrophobic linker connecting the histamine group to the backbone of the polymer that partly shields water (and, therefore, $\mathrm{H}^{+}$) and limits the histamine responsiveness. However, we found that NPs with $50 \%$ histamine tended to have lower release rates $(<65 \%$ drug release after $72 \mathrm{~h}$ at both $\mathrm{pH} 7.4$ 

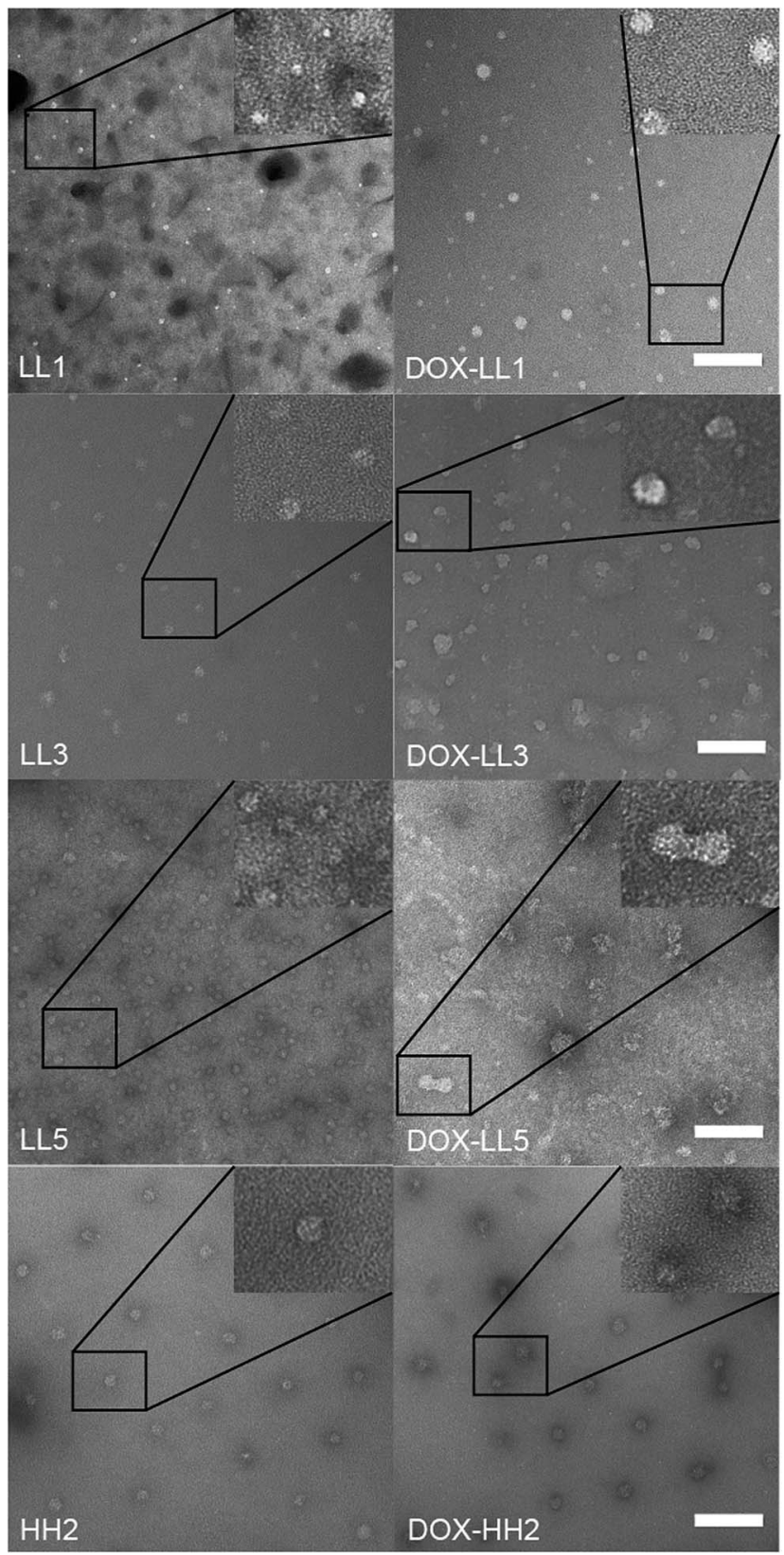

Fig. 2 TEM images of micelle solutions at pH 7.4. Scale bar $=100 \mathrm{~nm}$. Inset: 2.5 folds magnification of the selected areas. The average size of $\mathrm{LL1}=7 \mathrm{~nm}, \mathrm{DOX}-\mathrm{LL1}=11 \mathrm{~nm} ; \mathrm{LL3}=15 \mathrm{~nm}, \mathrm{DOX}-\mathrm{LL3}=17 \mathrm{~nm}$; LL5 = $10 \mathrm{~nm}, \mathrm{DOX}-\mathrm{LL} 5=19 \mathrm{~nm} ; \mathrm{HH} 2=13 \mathrm{~nm}, \mathrm{DOX}-\mathrm{HH} 2=15 \mathrm{~nm}$. The contrast has been enhanced for clarity.

and $\mathrm{pH}$ 6.0) compared to the other materials in the same group. This indicates that the overall architectural differences might contribute to the drug release kinetics but that the histamine responsiveness does not.

\subsection{Toxicity evaluation of NPs and DOX-NPs}

The initial screening of the NPs was performed using 3-(4,5dimethylthiazol-2-yl)-2,5-diphenyltetrazolium bromide (MTT) assays to evaluate the mitochondrial activity and partly reflects cellular viability. Cells were treated with either neat NPs or DOX- loaded NPs for 12 h, 24 h, or 72 h. No obvious loss of mitochondrial function was observed in the three breast cancer cell lines incubated with neat NPs at a high concentration $(100 \mu \mathrm{g}$ $\mathrm{mL}^{-1}$ ) of polymer after $12 \mathrm{~h}, 24 \mathrm{~h}$, or $72 \mathrm{~h}$ (Fig. ESI $4 \dagger$ ). However, significant reductions in mitochondrial activity were observed for the DOX-NP-treated cell lines, and the loss of activity was dependent on both concentration and time (Fig. 4A and ESI $5 \dagger$ ). It should be noticed that DOX-LL3 (50\% histamine) showed significant $(p<0.001)$ stronger toxicity compared to free DOX, DOX-LL1 (0\% histamine) and DOX-LL5 (100\% histamine) in all tested cell lines after 12 or $72 \mathrm{~h}$ treatment (Fig. $4 \mathrm{~A}$ ). In order to avoid false positive resulting from a single assay method, another sensitive viability test, the ATP CellTiter-Glo Luminescent cell viability assay, was used to check the viability of MDAMB-231 cells. This assay measures the amount of ATP from metabolically active cells, which is proportional to the number of living cells. ${ }^{69}$ Although the absolute values (Fig. ESI $6 \dagger$ ) were lower compared to the MTT assay at $72 \mathrm{~h}$ (Fig. 4A), the trends of DOX/DOX-NP efficacy towards MDA-MB-231 cells were the same in both assays.

Another interesting phenomenon was seen in Fig. ESI $5 \dagger$ where the majority of DOX-NPs induced similar or only slightly stronger effects on mitochondrial function when compared to free DOX after $72 \mathrm{~h}$ incubation, while they exhibited significantly stronger effects compared to free DOX at shorter $(12 \mathrm{~h})$ incubation times. Significantly, DOX-NPs only induced $(p<$ 0.001) higher degree of cellular apoptosis (PI-Annexin V staining) when compared to free DOX at the longer incubation time (Fig. 4B). This implies that the mechanism of how free DOX and DOX-NPs influences cancer cells might be different and that this difference enhances the efficacy of DOX-NPs in mitochondria function loss over shorter time frames. To verify the early effects of DOX-NPs on these cells and to investigate more subtle differences among the materials, a drug wash-out ${ }^{70,71}$ experiment was performed on the MDA-MB-468 cell line. This cell line was selected because it is commonly studied as a breast cancer mimic, for which doxorubicin is used as a therapy, as well as the relative sensitiveness to this drug. Three materials with $0 \%$, $50 \%$, and $100 \%$ histamine were selected from the lower molecular weight group (with shorter PEO blocks) and three were selected from the high molecular weight group (with longer PEO blocks). As shown in Fig. ESI 7, $\dagger$ after $4 \mathrm{~h}$ or $6 \mathrm{~h}$ incubation there were some reduced viability effects on the cells. It was, however, obvious after $24 \mathrm{~h}$ incubation that all six DOX-NPs had a significant effect $(p<0.001)$ in reducing mitochondrial function to $40-50 \%$ compared to the $20 \%$ reduction seen with free DOX with DOX-LL3 and DOX-LH3 having increased efficacy $(p<0.001)$ compared to the other DOX-NPs. These results imply that mechanisms other than simple inhibition of nuclear DNA replication contribute to early loss of mitochondrial function.

\subsection{Intracellular tracking of DOX-NPs in live cells}

In our previous study, we found that polymer NPs can be internalized into cells via both clathrin- and macropinocytosismediated endocytosis, and the amount of internalized NPs 
A

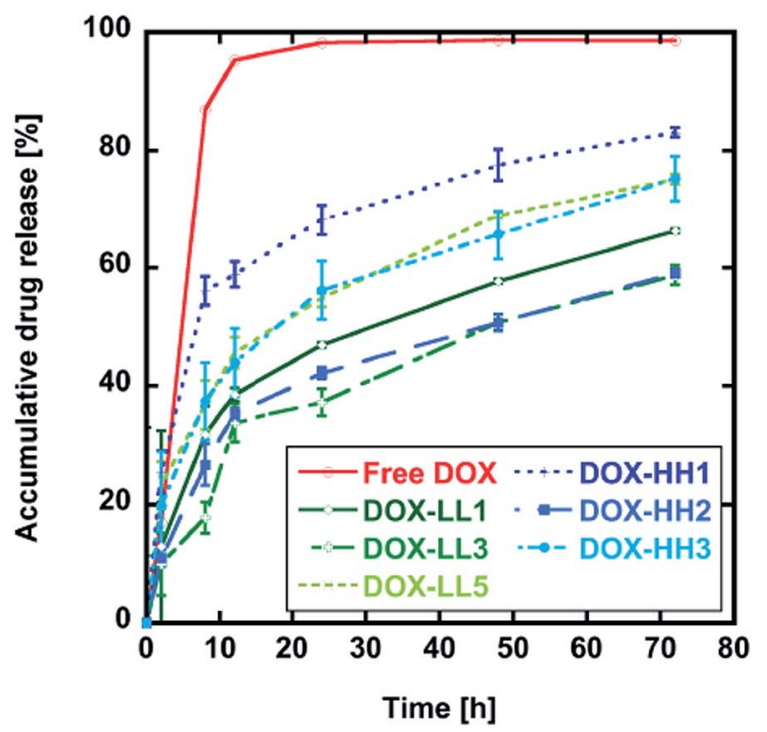

B

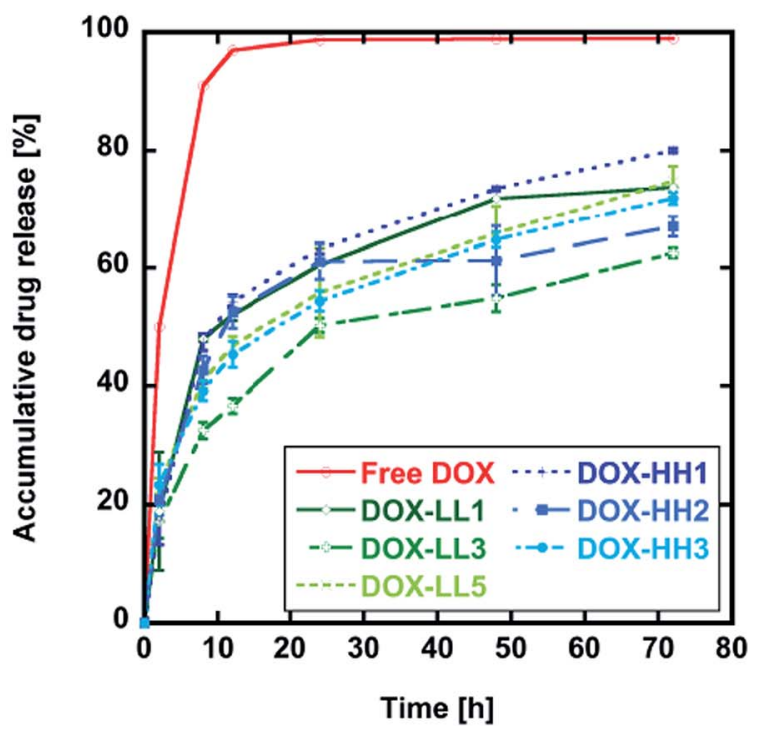

Fig. 3 In vitro DOX release at $37^{\circ} \mathrm{C}$. (A) DOX release in sodium phosphate buffer $\mathrm{pH}$ 6.0. (B) DOX release in PBS pH 7.4. Results are shown as mean $\pm \mathrm{SD}(n=3)$.

increases during $24 \mathrm{~h}$ of studies. ${ }^{59}$ For materials in this study we did not perform in depth uptake studies but can conclude that the uptake scales with time, and given the size probably via endocytosis mechanisms. In order to further investigate how and where the drug cargo of the NPs is delivered, we performed confocal microscopy investigations of the fluorescence-stained nuclei and organelles. DOX-LL3, DOX-LH3, and DOX-HH2 NPs were used to treat MDA-MB-468 cells to study their specific subcellular location. Four subcellular locations were selected based on our previous study, ${ }^{59}$ including the early endosome (EEA1), the lysosome (stained by LysoTracker), the trans-Golgi network (TGN), and the nucleus (stained by Hoechst 33 342). After $2 \mathrm{~h}$ treatment with $2 \mu \mathrm{g} \mathrm{mL} \mathrm{m}^{-1}$ DOX or DOX-NPs, DOX signals were mainly found overlapping the lysosome, mitochondria, and nucleus rather than in the early endosomes (EEA1) and the trans-golgi network (TGN) (Fig. 5A and ESI 8†), indicating partly evading the early endosome and the lysosome.

In order to further investigate and compare the degree of colocalization of DOX to different subcellular compartments, several parameters were calculated including Pearson's coefficient (P), the overlap coefficient (O), and Manders' coefficients M1 and M2. ${ }^{72}$ M1 reflects the portion of cellular components that co-localize with DOX, and M2 indicates the portion of DOX co-localized with cellular components. All of these coefficients were converted into a heat map (Fig. 5B) in which high values of $\mathrm{P}, \mathrm{O}$, and $\mathrm{M} 1$ are considered to be indicative of high co-localization while M2 is not. According to the heat map, high values of $\mathrm{P}, \mathrm{O}$, and $\mathrm{M} 1$ were found in the nuclei, lysosomes, and mitochondria indicating high levels of DOX distribution to these compartments. Lysosomes had the highest degree of colocalization to DOX, which was expected because lysosomes can entrap most exogenous substances, including drugs and smaller nanocarriers..$^{24,25}$ It is commonly assumed that histidine/histamine functional NPs ${ }^{44,45}$ can protect active drugs from the acidic environments of the endosomes and lysosomes until endosomal escape, cytosolic release, and uptake into the nucleus. It is very interesting to note that the $50 \%$ histaminecontaining NPs had strong DOX/nucleus co-localization within a short time period $(2 \mathrm{~h})$ which indicates that these NPs can escape from lysosomes.

Additional evidence supporting the hypothesis that DOXNPs can escape from lysosomes is that a strong co-localization exists between DOX-NPs (50\% histamine) and mitochondria in MDA-MB-468 cells. As seen in Fig. 5B, cells treated with free DOX have very strong co-localization with the nuclei and lysosomes but weaker overlap with the mitochondria. However, the three DOX-NPs exhibit stronger co-localization to the mitochondria compared to free DOX because they have higher values of P, O, and M1. Moreover, DOX-LL3 and DOX-HH2 showed decreased co-localization to lysosomes. These observations suggest that histamine modified NPs (50\% histamine) can partly avoid entrapment in lysosomes and can deliver the DOX to other regions in the MDA-MB-468 cells within $2 \mathrm{~h}$.

In addition, the enhanced DOX distribution in mitochondria may explain why greater losses of mitochondrial activity are seen when the cells were treated with DOX-NPs compared to free DOX over short time periods (12-24 h, Fig. 4A, ESI 5 and ESI $7 \dagger)$. The mitochondria have their own DNA apart from nuclear DNA, called mitochondria DNA (mtDNA), that encodes 13 polypeptides required for respiratory chain proteins and $12 \mathrm{~S}$ rRNAs, 16S rRNAs, and 22 tRNAs needed in protein synthesis. ${ }^{73}$ Because of the irreplaceable role of the mitochondria in cellular metabolism, more and more researchers consider the mitochondria as a potential target for cancer therapy. ${ }^{74,75}$ As an anthracycline antibiotic, DOX can intercalate into nuclear DNA to inhibit cell proliferation and interfere with topoisomerase II 
A
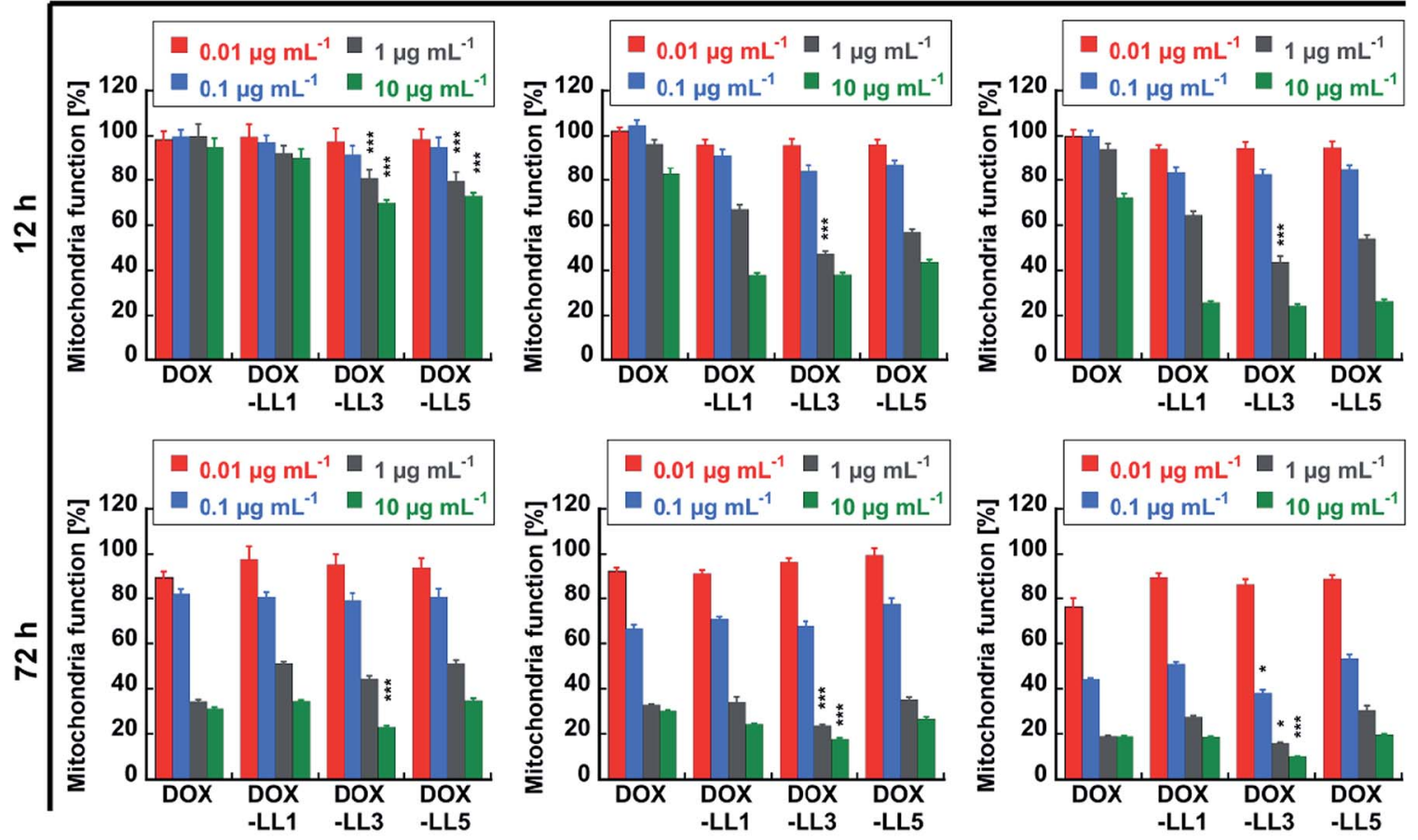

B
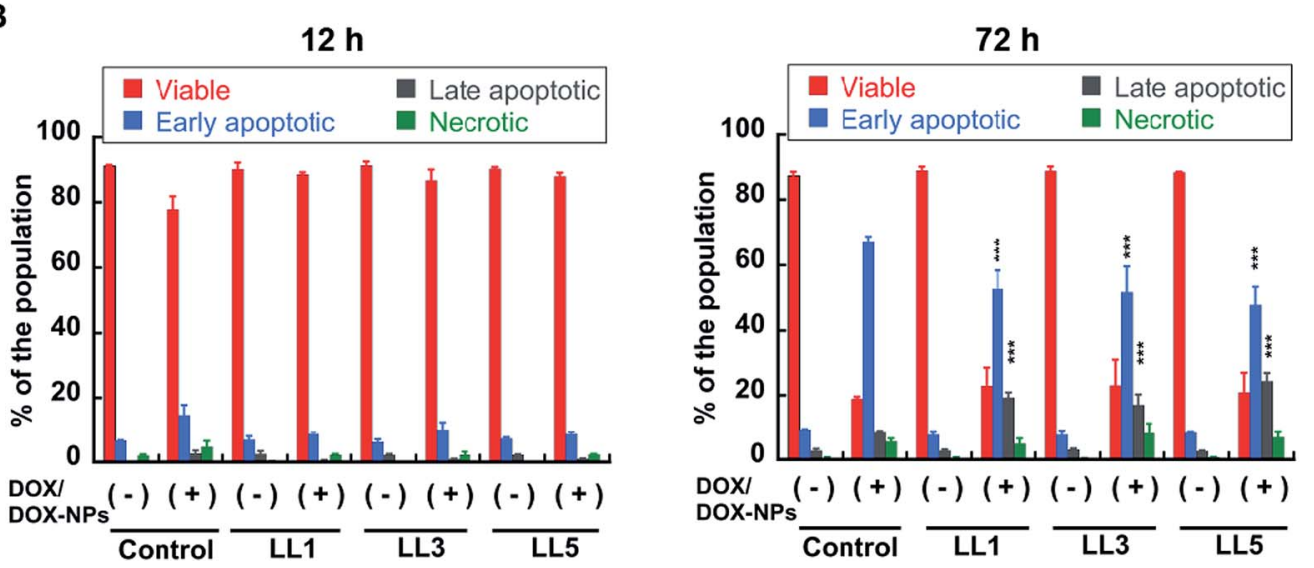

Fig. 4 Toxicity assays of DOX-NPs. (A) Impairment of mitochondrial function as a result of treatment with DOX-loaded NPs. MTT assays after incubating DOX-NPs for $12 \mathrm{~h}$ or $72 \mathrm{~h}$ with breast cancer cell lines MDA-MB-231, MDA-MB-468, and MCF-7. Results are shown as mean \pm SD ( $n=$ 5). (B) Apoptosis \& Necrosis assays of DOX-NPs against MDA-MB-468 cells. Cells were incubated with $1 \mu \mathrm{g} \mathrm{mL} \mathrm{mLX}^{-1} \mathrm{DOX}-\mathrm{NPs}$ for $12 \mathrm{~h}$ or $72 \mathrm{~h}$, then collected and stained with PI and Annexin-V FITC. Results are shown as mean \pm SD $(n=3)$. $p<0.05$ and ***p $<0.001$ compared to the control/ other groups.

resulting in DNA damage. ${ }^{76}$ It has also been shown that DOX can also interfere with mtDNA. ${ }^{77}$ Therefore, we propose that DOX-NPs may be able to localize more DOX to the mitochondria and accelerate the disruption of mtDNA with subsequent loss of mitochondrial function leading to cell death, supported by the significant increase in late apoptosis in cells treated by DOXNPs compared to free DOX (Fig. 4B). Similar strategies for cisplatin delivery to mitochondria have been explored in an effort to overcome resistance in central nervous system cancers. ${ }^{53}$ Further toxicological analysis of silver nanoparticles suggests they change the mitochondrial membrane permeability and hence give rise to cell death. ${ }^{78}$ Similarly, silica NPs have one of their main mechanism of cytotoxicity via induction of oxidative stress and as a consequence result in mitochondrial membrane potential changes and apoptosis. ${ }^{79}$ Similar results have been found for positively charged triblock copolymer NPs. ${ }^{80}$ This will contribute to increased cell death when compared to other DOX conjugates and delivery systems. ${ }^{81}$ Also by localization of the drug carrying NP to the mitochondria instead of the lysosome less DOX will be detoxified by the lower $\mathrm{pH}$ in the endo-lysosomal compartment. We also considered investigating the influence of NPs on the levels of reactive oxygen species that is balanced by mitochondria. ${ }^{82}$ However, due to small numbers of remaining allyl groups in the NPs, 
A

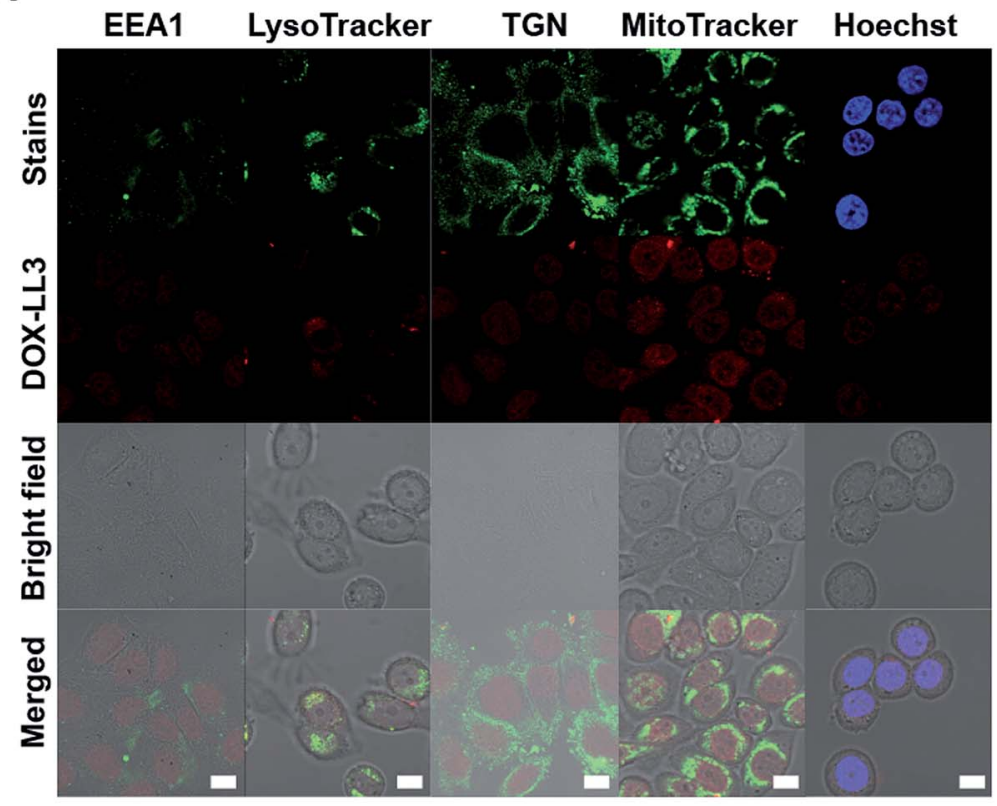

B
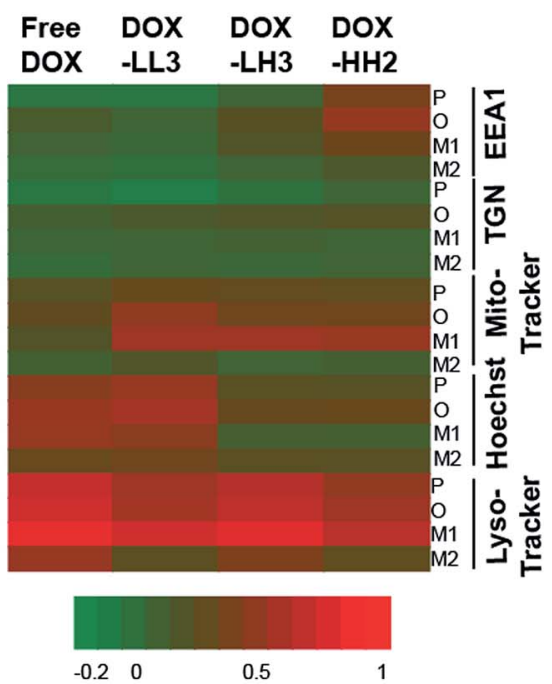

C

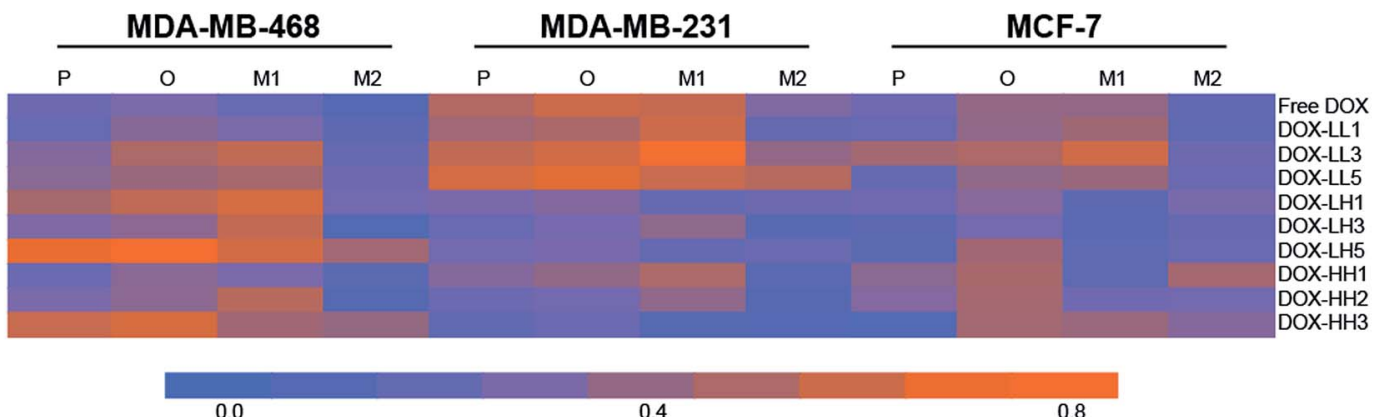

Fig. 5 Intracellular distribution of DOX-NPs in 2D culture models. (A) Confocal images of DOX-LL3 in MDA-MB-468 cells. Cells were treated with $2 \mu \mathrm{g} \mathrm{mL}{ }^{-1}$ DOX-NPs for $2 \mathrm{~h}$. Different cell organelles were labelled with specific dyes with deep red fluorescence represented as false green colour. Early endosomes (EEA1) and Golgi (TGN) were visualized with the primary antibody before labelling with secondary antibody (deep red). Nuclei were stained by Hoechst 33342 dye (blue). Co-localizations between organelles and DOX and between nuclei and DOX in the merged images are seen as yellow and purple, respectively. Scale bar $=10 \mu \mathrm{m}$. (B) The heat map of the co-localization parameters of DOX-LL3, DOX$\mathrm{LH} 3$, and DOX-HH2 in different parts of the MDA-MB-468 cells. (C) Heat map of the co-localization between DOX-NPs and the mitochondria in three breast cancer cells. In (B) and (C), $P=$ Pearson's coefficient, $O=$ overlap coefficient, $M=$ Manders' coefficients, $M 1=$ fraction of cell positions overlapping DOX-NPs, and M2 = fraction of DOX-NPs overlapping cell positions.

which are undetectable by NMR, it is impossible to obtain reliable data on ROS generation by these materials as the allyl groups may act as radical scavengers in these types of assays.

Based on the assumption that His-NPs can increase drug accumulation in mitochondria, we further explored the impact of our NPs on the three breast cancer cell lines in order to find out whether this accumulation is common in breast cancer cells and if there are any variations among the different carriers. According to the merged images in Fig. ESI $8 \mathrm{~B} \dagger$ and the heat map of the parameters for co-localization to the mitochondria in Fig. 5C, the low PXGE molecular weight (Mw), low PEO Mw group (LL1, LL3, LL5) tends to have enhanced mitochondria localization in the three breast cancer cells compared to free DOX. Among these, DOX-LL3 exhibits the highest co- localization according to the high values of $\mathrm{P}, \mathrm{O}$, and $\mathrm{M} 1$. The low PXGE, high PEO Mw group (LH1, LH3, LH5) tends to have lower co-localization to the mitochondria in MDA-MB-231 and MCF-7 cells, and this suggests that the molecular weight and structure of His-NPs might influence the distribution of the drug into the mitochondria. Except for DOX-LL3, no obvious differences among different compositions of the NPs in the library were observed.

\subsection{D breast cancer cell culture and viability assays}

It have also been suggested that 3D cell models might better represent the in vivo situation than 2D cell cultures. ${ }^{57}$ This is because the 3D spheroid structure provides increased drug resistance, the formation of oxygen and nutrient gradients, and 
A

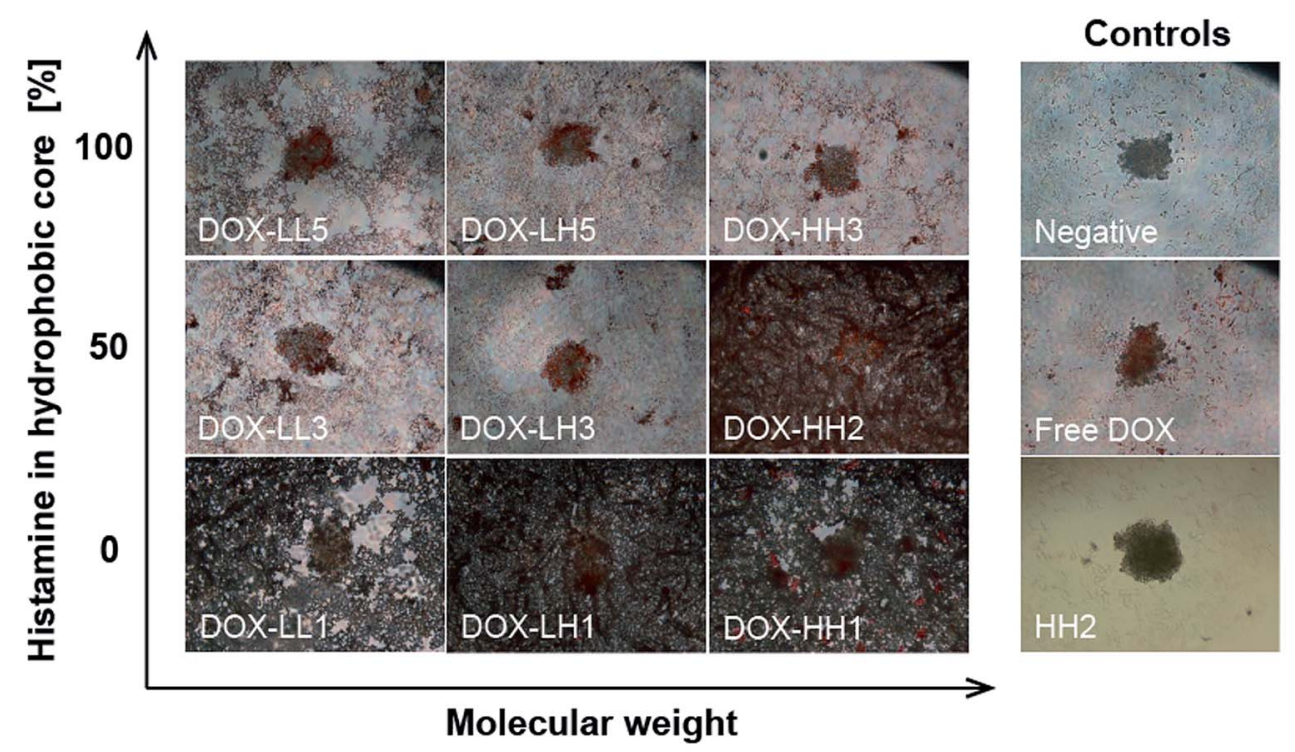

B

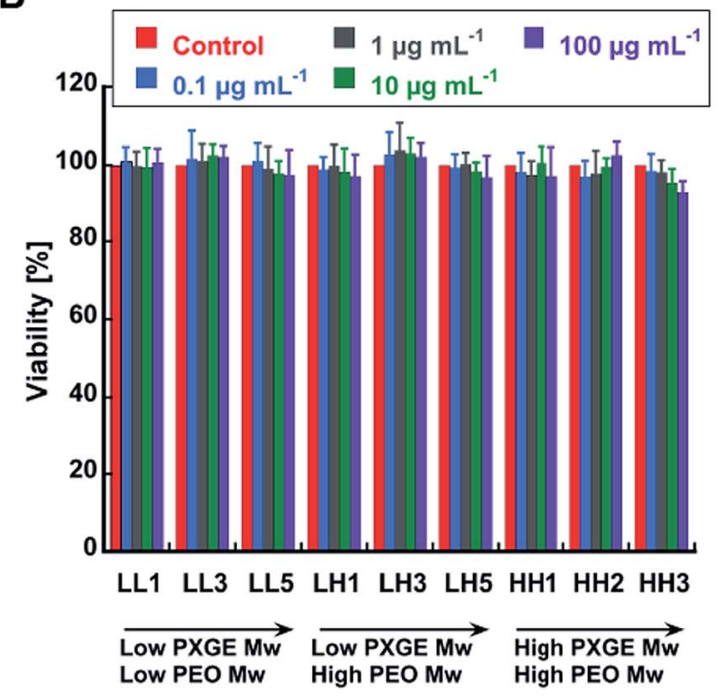

C

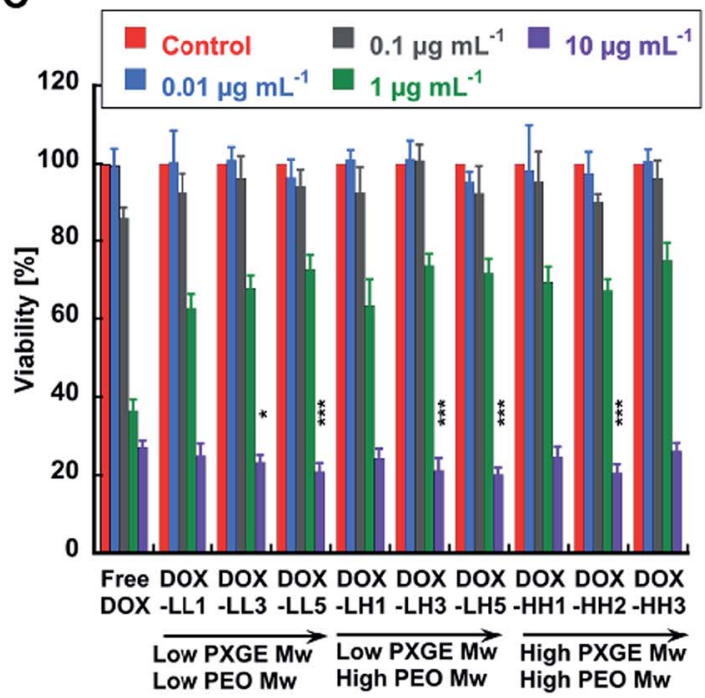

Fig. 6 The effects of DOX-NPs on the 3D cell culture model. (A) Morphological changes of MDA-MB-231 spheroids treated with $10 \mu \mathrm{g} \mathrm{mL}^{-1}$ DOX-NPs or DOX or $100 \mu \mathrm{g} \mathrm{mL}^{-1} \mathrm{NPs}$ after $72 \mathrm{~h}$. ATP luminance assays for 3D spheroids after $72 \mathrm{~h}$ treatment with pure NPs (B) and DOX-NPs (C). Results are shown as mean $\pm \mathrm{SD}(n=6) . * p<0.05$ and $* * * p<0.001$ compared to control.

partially necrotic areas, all of which are features of in vivo tumours. Davis et al. ${ }^{83}$ utilized such models in NP studies and observed the internalization of chemotherapeutics into the spheroids by confocal microscopy. However, they did not provide any co-localization information in these studies and did not show a reliable measurement of cellular viability in the 3D model. The viability assessment is crucial because such quantitative data can provide convincing evidence for the efficacy of the drug-NPs. Therefore, we developed a 3D cell culture model using MDA-MB-231 cells and assessed cell viability with the ATP CellTiter-Glo® luminescent cell viability assay, which measures the concentration of ATP as a direct reflection of the number of living cells. This method is suitable for measuring cellular viability in $3 \mathrm{D}$ spheroids as a function of NP dose because it lyses the cells and the total ATP content can be measured. In contrast, MTT reagents have poor spheroid penetration and false results of mitochondrial function are often observed.

In this study, we observed obvious structural damage to the spheroids caused by DOX-NPs after $72 \mathrm{~h}$ incubation compared to untreated, free DOX-treated, and neat NP-treated spheroids (Fig. 6A). NPs with $0 \%$ histamine led to a total structural collapse of the spheroid, and none of the DOX-NPs with $100 \%$ histamine resulted in complete disintegration. It is notable that DOX-HH2 (50\% histamine)-treated spheroids also disintegrated and showed the greatest effect in the viability assay. This indicates that the polymer composition has a strong effect on the spheroid morphology and stability that is not related to the viability effects from the delivered drug but rather linked to a 


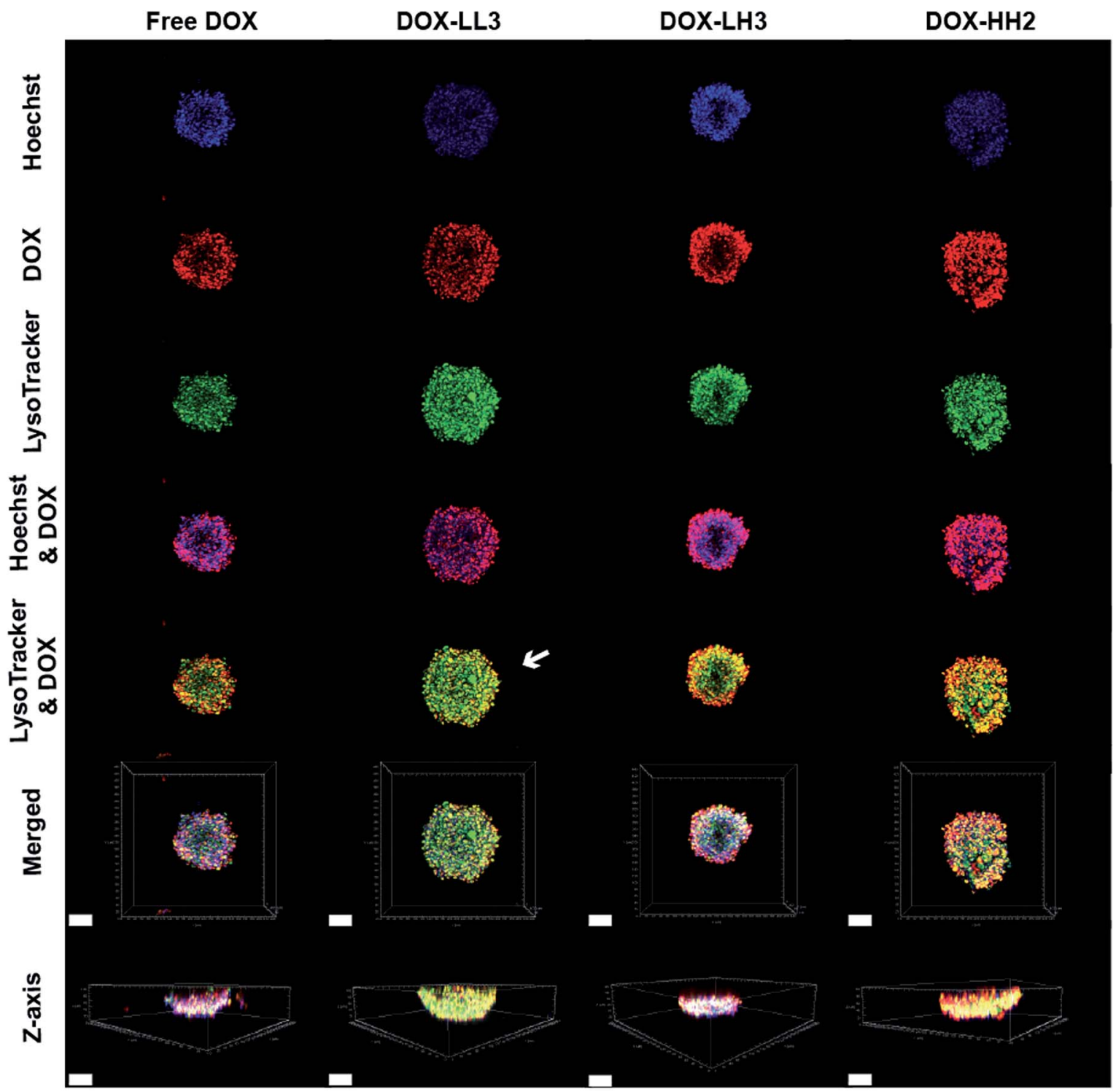

Fig. 7 Live cell imaging of DOX distribution in MDA-MB-231 3D spheroids. Spheroids were treated with $2 \mu \mathrm{g} \mathrm{mL} \mathrm{LOX}^{-1}$ or DOX-NPs for $4 \mathrm{~h}$. Nuclei were stained with Hoechst 33342 represented in blue, and lysosomes were stained with LysoTracker deep red and represented as a false green colour. The white arrow points out the lower level of co-localization between DOX-NPs and Lysotracker. Images were analyzed and reconstructed with Imars software. Scale bar $=70 \mu \mathrm{m}$.

surfactant-like effect. In order to evaluate the efficacy of the DOX-NPs and to investigate whether the loss of structural integrity in the spheroids was related to lower viability, we utilized the CellTiter-Glo luminescent cell viability assay. As expected, neat NPs did not introduce any significant viability loss at the highest concentration tested $\left(100 \mu \mathrm{g} \mathrm{mL}^{-1}\right)$ after $72 \mathrm{~h}$ (Fig. 6B). This is similar to the 2D MTT results in Fig. ESI $4 . \dagger$ However, DOX-NPs led to more than $75 \%$ viability loss at $10 \mu \mathrm{g}$ $\mathrm{mL}^{-1}$ DOX-equivalent concentration. In particular, DOX-NPs with $50 \%$ and $100 \%$ histamine content exhibited significantly stronger toxicity towards spheroids compared to free DOX ( $p<$ 0.05 and $p<0.001$, respectively) (Fig. 6C). Thus, we can conclude that NPs without histamine have an enhanced effect on breaking down the 3D structures, while NPs with histamine can trigger higher DOX efficacy in MDA-MB-231 3D models.

\subsection{DOX localization studies in 3D spheroids}

In order to further track the localization of the DOX internalized in the $3 \mathrm{D}$ spheroids, we performed live cell imaging of $3 \mathrm{D}$ spheroids. The projection images were reconstructed with Imars software. Spheroids were treated with DOX or DOX-NPs for $4 \mathrm{~h}$ then stained with Hoechst 33342 and LysoTracker or MitoTracker. The fluorescence images in Fig. 7 show that the surfaces of the spheroids are not homogenous and that there are channels in the spheroids. All of the spheroids displayed good co-localization of DOX within the nuclei, but DOX-LL3treated spheroids demonstrated weaker co-localization between the drug and lysosome - as highlighted by the white arrow in Fig. 7 - indicating possible escape of DOX-LL3 from lysosomes in the surface layer of cells with penetration of the spheroid to a 
greater degree than free DOX or other DOX-NPs. However, light penetration into the core of the spheroid is not efficient due to its condensed nature, and a complete $3 \mathrm{D}$ image of the spheroid cannot be obtained. This limits the full evaluation of the penetration of the spheroid, but this is similar to the case of a real tumour. We also attempted to stain the spheroids with the MitoTracker deep red FM dye. ${ }^{\mathbf{4}}$ Unfortunately, this dye also does not penetrate sufficiently deep into the spheroids (Fig. ESI 9†).

\section{Conclusions}

In this study, a library of polymer nanoparticles based on structurally different diblock copolymer starting materials, including a range of histamine-functionalized systems, was synthesized via a combination of ring-opening polymerization and thiol-ene click chemistry and used to assemble polymer NPs with charge reversal properties. All materials were found to be non-toxic in three breast cancer cell lines and all were able to encapsulate DOX. No strong $\mathrm{pH}$-responsive properties were found in the in vitro release experiments, but the $50 \%$ histamine-modified NPs displayed lower drug release rates after $72 \mathrm{~h}$ at both pH 6 and pH 7. Further studies of the drug distribution in cells suggest that DOX-NPs are capable of escaping from endosomes and lysosomes and can deliver DOX into the nucleus and the mitochondria within $2 \mathrm{~h}$. Moreover, DOX-NPs displayed similar efficacy as free DOX after $72 \mathrm{~h}$ treatment in the breast cancer cell lines MCF-7, MDA-MB-231, and MDA-MB-468, but were found to be more effective at shorter times due to their mitochondria localization. NPs containing 50\% histamine can partly escape from lysosomes and deliver DOX into the nucleus in our established 3D spheroid model. These results suggest that histamine-functionalized NPs are a promising building block/scaffold for drug delivery systems, especially targeting the mitochondria section.

\section{Acknowledgements}

This work was partially supported by the National Institutes of Health as a Program of Excellence in Nanotechnology (HHSN268201000046C) (NAL, CJH) and the National Science Foundation through the MRSEC program DMR-1121053 (NAL, PL, CJH). PL would like to acknowledge the Wenner-Gren and Bengt Lundqvist foundations for financial support. AMN acknowledges financial support from STINT, Karolinska Institutet, Percy Falks Foundation, and The Swedish Research Council (VR) 2009-3259 and 2011-3720.

\section{Notes and references}

1 A. Guiseppi-Elie, C. B. Dong and C. Z. Dinu, J. Mater. Chem., 2012, 22, 19529-19539.

2 J. Wu, N. Kamaly, J. J. Shi, L. L. Zhao, Z. Y. Xiao, G. Hollett, R. John, S. Ray, X. Y. Xu, X. Q. Zhang, P. W. Kantoff and O. C. Farokhzad, Angew. Chem., Int. Ed., 2014, 53, 8975-8979. 3 M. Sanjoh, S. Hiki, Y. Lee, M. Oba, K. Miyata, T. Ishii and K. Kataoka, Macromol. Rapid Commun., 2010, 31, 1181-1186.
4 H. Takemoto, K. Miyata, S. Hattori, T. Ishii, T. Suma, S. Uchida, N. Nishiyama and K. Kataoka, Angew. Chem., Int. Ed., 2013, 52, 6218-6221.

5 R. G. Qi, S. Liu, J. Chen, H. H. Xiao, L. S. Yan, Y. B. Huang and X. B. Jing, J. Controlled Release, 2012, 159, 251-260.

6 H. H. Xiao, H. Q. Song, Q. Yang, H. D. Cai, R. G. Qi, L. S. Yan, S. Liu, Y. H. Zheng, Y. B. Huang, T. J. Liu and X. B. Jing, Biomaterials, 2012, 33, 6507-6519.

7 H. H. Xiao, H. Q. Song, Y. Zhang, R. G. Qi, R. Wang, Z. G. Xie, Y. B. Huang, Y. X. Li, Y. Wu and X. B. Jing, Biomaterials, 2012, 33, 8657-8669.

8 Z. Q. Yu, R. M. Schmaltz, T. C. Bozeman, R. Paul, M. J. Rishel, K. S. Tsosie and S. M. Hecht, J. Am. Chem. Soc., 2013, 135, 2883-2886.

9 S. Wong, M. S. Shim and Y. J. Kwon, J. Mater. Chem. B, 2014, 2, 595-615.

10 S. Kim, M. J. Stebe, J. L. Blin and A. Pasc, J. Mater. Chem. B, 2014, 2, 7910-7917.

11 K. Kataoka, A. Harada and Y. Nagasaki, Adv. Drug Delivery Rev., 2001, 47, 113-131.

12 A. Blanazs, S. P. Armes and A. J. Ryan, Macromol. Rapid Commun., 2009, 30, 267-277.

13 A. N. Lukyanov and V. P. Torchilin, Adv. Drug Delivery Rev., 2004, 56, 1273-1289.

14 V. P. Sant, D. Smith and J. C. Leroux, J. Controlled Release, 2004, 97, 301-312.

15 Z. G. Gao, A. N. Lukyanov, A. Singhal and V. P. Torchilin, Nano Lett., 2002, 2, 979-982.

16 I. Brigger, C. Dubernet and P. Couvreur, Adv. Drug Delivery Rev., 2002, 54, 631-651.

17 M. Ferrari, Nat. Rev. Cancer, 2005, 5, 161-171.

18 M. E. Davis, Z. Chen and D. M. Shin, Nat. Rev. Drug Discovery, 2008, 7, 771-782.

19 A. Schroeder, D. A. Heller, M. M. Winslow, J. E. Dahlman, G. W. Pratt, R. Langer, T. Jacks and D. G. Anderson, Nat. Rev. Cancer, 2012, 12, 39-50.

20 R. A. Petros and J. M. DeSimone, Nat. Rev. Drug Discovery, 2010, 9, 615-627.

21 M. E. Fox, F. C. Szoka and J. M. J. Frechet, Acc. Chem. Res., 2009, 42, 1141-1151.

22 Y. Matsumura and H. Maeda, Cancer Res., 1986, 46, 63876392.

23 D. Peer, J. M. Karp, S. Hong, O. C. FaroKHzad, R. Margalit and R. Langer, Nat. Nanotechnol., 2007, 2, 751-760.

24 C. L. Tseng, T. W. Wang, G. C. Dong, S. Y. H. Wu, T. H. Young, M. J. Shieh, P. J. Lou and F. H. Lin, Biomaterials, 2007, 28, 3996-4005.

25 H. Y. Nam, S. M. Kwon, H. Chung, S. Y. Lee, S. H. Kwon, H. Jeon, Y. Kim, J. H. Park, J. Kim, S. Her, Y. K. Oh, I. C. Kwon, K. Kim and S. Y. Jeong, J. Controlled Release, 2009, 135, 259-267.

26 L. A. Bareford and P. W. Swaan, Adv. Drug Delivery Rev., 2007, 59, 748-758.

27 P. K. Selbo, A. Weyergang, A. Hogset, O. J. Norum, M. B. Berstad, M. Vikdal and K. Berg, J. Controlled Release, 2010, 148, 2-12. 
28 J. K. Vasir and V. Labhasetwar, Adv. Drug Delivery Rev., 2007, 59, 718-728.

29 J. Panyam, W. Z. Zhou, S. Prabha, S. K. Sahoo and V. Labhasetwar, FASEB J., 2002, 16, 1217-1226.

30 L. E. Gerweck and K. Seetharaman, Cancer Res., 1996, 56, 1194-1198.

31 K. Miyata, N. Nishiyama and K. Kataoka, Chem. Soc. Rev., 2012, 41, 2562-2574.

32 E. S. Lee, Z. G. Gao and Y. H. Bae, J. Controlled Release, 2008, 132, 164-170.

33 I. F. Tannock and D. Rotin, Cancer Res., 1989, 49, 4373-4384.

34 A. Sorkin and M. von Zastrow, Nat. Rev. Mol. Cell Biol., 2002, 3, 600-614.

35 A. E. Nel, L. Madler, D. Velegol, T. Xia, E. M. V. Hoek, P. Somasundaran, F. Klaessig, V. Castranova and M. Thompson, Nat. Mater., 2009, 8, 543-557.

36 A. K. Varkouhi, M. Scholte, G. Storm and H. J. Haisma, J. Controlled Release, 2011, 151, 220-228.

37 W. T. Godbey, K. K. Wu and A. G. Mikos, J. Controlled Release, 1999, 60, 149-160.

38 H. T. Lv, S. B. Zhang, B. Wang, S. H. Cui and J. Yan, J. Controlled Release, 2006, 114, 100-109.

39 M. Oishi, K. Kataoka and Y. Nagasaki, Bioconjugate Chem., 2006, 17, 677-688.

40 M. P. Xiong, Y. Bae, S. Fukushima, M. L. Forrest, N. Nishiyama, K. Kataoka and G. S. Kwon, ChemMedChem, 2007, 2, 1321-1327.

41 F. Pittella, M. Z. Zhang, Y. Lee, H. J. Kim, T. Tockary, K. Osada, T. Ishii, K. Miyata, N. Nishiyama and K. Kataoka, Biomaterials, 2011, 32, 3106-3114.

42 Y. Kakizawa, S. Furukawa, A. Ishii and K. Kataoka, J. Controlled Release, 2006, 111, 368-370.

43 J. S. Park, T. H. Han, K. Y. Lee, S. S. Han, J. J. Hwang, D. H. Moon, S. Y. Kim and Y. W. Cho, J. Controlled Release, 2006, 115, 37-45.

44 R. Shrestha, M. Elsabahy, S. Florez-Malaver, S. Samarajeewa and K. L. Wooley, Biomaterials, 2012, 33, 8557-8568.

45 K. L. Chang, Y. Higuchi, S. Kawakami, F. Yamashita and M. Hashida, Bioconjugate Chem., 2010, 21, 1087-1095.

46 J. J. Gu, X. Wang, X. Y. Jiang, Y. Z. Chen, L. C. Chen, X. L. Fang and X. Y. Sha, Biomaterials, 2012, 33, 644-658.

47 Y. T. Wen, Z. H. Guo, Z. Du, R. Fang, H. M. Wu, X. Zeng, C. Wang, M. Feng and S. R. Pan, Biomaterials, 2012, 33, 8111-8121.

$48 \mathrm{H}$. Wu, L. Zhu and V. P. Torchilin, Biomaterials, 2013, 34, 1213-1222.

49 R. Liu, D. Li, B. He, X. H. Xu, M. M. Sheng, Y. S. Lai, G. Wang and Z. W. Gu, J. Controlled Release, 2011, 152, 49-56.

50 C. M. Yu, C. M. Gao, S. Y. Lu, C. Chen, J. L. Yang, X. Di and M. Z. Liu, Colloids Surf., B, 2014, 115, 331-339.

51 P. Lundberg, N. A. Lynd, Y. Zhang, X. Zeng, D. V. Krogstad, T. Paffen, M. Malkoch, A. M. Nystrom and C. J. Hawker, Soft Matter, 2013, 9, 82-89.

52 R. Savic, L. B. Luo, A. Eisenberg and D. Maysinger, Science, 2003, 300, 615-618.

53 S. Marrache, R. K. Pathak and S. Dhar, Proc. Natl. Acad. Sci. U. S. A., 2014, 111, 10444-10449.
54 L. M. Wang, Y. Liu, W. Li, X. M. Jiang, Y. L. Ji, X. C. Wu, L. G. Xu, Y. Qiu, K. Zhao, T. T. Wei, Y. F. Li, Y. L. Zhao and C. Y. Chen, Nano Lett., 2011, 11, 772-780.

55 C. Porsch, Y. Zhang, A. Ostlund, P. Damberg, C. Ducani, E. Malmstrom and A. M. Nystrom, Part. Part. Syst. Charact., 2013, 30, 381-390.

56 C. Porsch, Y. Zhang, C. Ducani, F. Vilaplana, L. Nordstierna, E. Malmstrom and A. M. Nystrom, Biomacromolecules, 2014, 15, 2235-2245.

57 P. Longati, X. H. Jia, J. Eimer, A. Wagman, M. R. Witt, S. Rehnmark, C. Verbeke, R. Toftgard, M. Lohr and R. L. Heuchel, BMC Cancer, 2013, 13, 95.

58 X. Zeng, R. Morgenstern and A. M. Nystrom, Biomaterials, 2014, 35, 1227-1239.

59 X. Zeng, Y. Zhang and A. M. Nystrom, Biomacromolecules, 2012, 13, 3814-3822.

60 W. C. Shen, Biochim. Biophys. Acta, 1990, 1034, 122-124.

61 S. B. Luo, R. Cheng, F. H. Meng, T. G. Park and Z. Y. Zhong, J. Polym. Sci., Part A: Polym. Chem., 2011, 49, 3366-3373.

62 C. E. Hoyle and C. N. Bowman, Angew. Chem., Int. Ed., 2010, 49, 1540-1573.

63 R. K. Iha, K. L. Wooley, A. M. Nystrom, D. J. Burke, M. J. Kade and C. J. Hawker, Chem. Rev., 2009, 109, 5620-5686.

64 X. Zeng, Y. Zhang, Z. Wu, P. Lundberg, M. Malkoch and A. M. Nyström, J. Polym. Sci., Part A: Polym. Chem., 2012, 50, 280-288.

65 Y. Hed, Y. Zhang, O. C. J. Andren, X. Zeng, A. M. Nystrom and M. Malkoch, J. Polym. Sci., Part A: Polym. Chem., 2013, 51, 3992-3996.

66 Z. Wu, X. Zeng, Y. Zhang, N. Feliu, P. Lundberg, B. Fadeel, M. Malkoch and A. M. Nystrom, J. Polym. Sci., Part A: Polym. Chem., 2012, 50, 217-226.

67 V. P. Torchilin, J. Controlled Release, 2001, 73, 137-172.

68 E. R. Gillies and J. M. J. Frechet, Bioconjugate Chem., 2005, 16, 361-368.

69 T. L. Riss and R. A. Moravec, Assay Drug Dev. Technol., 2004, 2, 51-62.

70 A. Azzariti, G. Bocci, L. Porcelli, A. Fioravanti, P. Sini, G. M. Simone, A. E. Quatrale, P. Chiarappa, A. Mangia, S. Sebastian, D. Del Bufalo, M. Del Tacca and A. Paradiso, Br. J. Cancer, 2011, 104, 769-780.

71 L. Wang, J. Wang, B. W. Blaser, A. M. Duchemin, D. F. Kusewitt, T. Liu, M. A. Caligiuri and R. Briesewitz, Blood, 2007, 110, 2075-2083.

72 S. Bolte and F. P. Cordelieres, J. Microsc., 2006, 224, 213-232. 73 P. Huang and J. S. Carew, Mol. Cancer, 2002, 1, 9.

74 S. Fulda, L. Galluzzi and G. Kroemer, Nat. Rev. Drug Discovery, 2010, 9, 447-464.

75 E. L. Zhang, C. Zhang, Y. P. Su, T. M. Cheng and C. M. Shi, Drug Discovery Today, 2011, 16, 140-146.

76 D. A. Gewirtz, Biochem. Pharmacol., 1999, 57, 727-741.

77 N. Ashley and J. Poulton, Biochem. Biophys. Res. Commun., 2009, 378, 450-455.

78 J. S. Teodoro, A. M. Simoes, F. V. Duarte, A. P. Rolo, R. C. Murdoch, S. M. Hussain and C. M. Palmeira, Toxicol. in Vitro, 2011, 25, 664-670. 
79 L. Sun, Y. Li, X. M. Liu, M. H. Jin, L. Zhang, Z. J. Du, C. X. Guo, P. L. Huang and Z. W. Sun, Toxicol. in Vitro, 2011, 25, 1619-1629.

80 S. Bhattacharjee, D. Ershov, K. Fytianos, J. van der Gucht, G. M. Alink, I. M. C. M. Rietjens, A. T. M. Marcelis and H. Zuilhof, Part. Fibre Toxicol., 2012, 9, 11.

81 X. B. Xiong, Z. S. Ma, R. Lai and A. Lavasanifar, Biomaterials, 2010, 31, 757-768.
82 J. F. Turrens, J. Physiol., 2003, 552, 335-344.

83 J. S. Basuki, H. T. T. Duong, A. Macmillan, R. B. Erlich, L. Esser, M. C. Akerfeldt, R. M. Whan, M. Kavallaris, C. Boyer and T. P. Davis, ACS Nano, 2013, 7, 10175-10189.

84 K. Okabe, N. Inada, C. Gota, Y. Harada, T. Funatsu and S. Uchiyama, Nat. Commun., 2012, 3, 705. 